\author{
UNIVERSIDADE DE SÃO PAULO \\ FACULDADE DE MEDICINA DE RIBEIRÃO PRETO \\ DEPARTAMENTO DE BIOQUÍMICA E IMUNOLOGIA \\ PÓS-GRADUAÇÃO EM IMUNOLOGIA BÁSICA E APLICADA
}

\title{
Papel das Neutrophil Extracellular Traps no controle da infecção por Chikungunya
}

Carlos Hiroji Hiroki

Ribeirão Preto 


\author{
UNIVERSIDADE DE SÃO PAULO \\ FACULDADE DE MEDICINA DE RIBEIRÃO PRETO \\ DEPARTAMENTO DE BIOQUÍMICA E IMUNOLOGIA \\ PÓS-GRADUAÇÃO EM IMUNOLOGIA BÁSICA E APLICADA
}

\title{
Papel das Neutrophil Extracellular Traps no controle da infecção por Chikungunya
}

Carlos Hiroji Hiroki

Dissertação apresentada ao Programa de PósGraduação em Imunologia Básica e Aplicada da Faculdade de Medicina de Ribeirão Preto da Universidade de São Paulo, para a obtenção do título de Mestre em Ciências. Área de Concentração: Imunologia Básica e Aplicada.

Orientador: Prof. Dr. Fernando de Queiroz Cunha

Ribeirão Preto 
Autorizo a reprodução e divulgação total ou parcial deste trabalho, por qualquer meio convencional ou eletrônico, para fins de estudo e pesquisa, desde que citada a fonte.

FICHA CATALOGRÁFICA

Hiroki, Carlos Hiroji
Papel das Neutrophil Extracellular Traps no controle da
infecção por Chikungunya. Ribeirão Preto, 2017
73p.
Dissertação de Mestrado, apresentada ao Programa de Pós-
Graduação em Imunologia Básica e Aplicada da Faculdade de Medicina
de Ribeirão Preto da Universidade de São Paulo para obtenção do título
de Mestre em Ciências. Área de concentração: Imunologia Básica e
Aplicada


Nome: Carlos Hiroji Hiroki

Título: Papel das Neutrophil Extracellular Traps no controle da infecção por Chikungunya.

Dissertação apresentada ao Programa de PósGraduação em Imunologia Básica e Aplicada da Faculdade de Medicina de Ribeirão Preto da Universidade de São Paulo, para a obtenção do título de Mestre em Ciências. Área de Concentração: Imunologia Básica e Aplicada

Aprovado em:

\section{Banca Examinadora}

Prof. Dr. Fernando de Queiroz Cunha. Instituição: Faculdade de Medicina de Ribeirão Preto Julgamento: Assinatura

Prof. Dr Luiz Tadeu Moraes Figueiredo: Faculdade de Medicina de Ribeirão Preto Julgamento: Assinatura

Prof .Dr. Jean Pierre Schatzmann: Instituto de Ciências Biomédicas - USP Julgamento: Assinatura

Profa. Dra. Karina Alves de Toledo: Faculdade de Ciências e Letras - UNESP - ASSIS Julgamento: Assinatura 
Dedico este trabalho à minha família.

Serei eternamente grato por todo apoio, carinho e incentivo a correr atrás de meus sonhos. 


\section{AGRADECIMENTOS}

À minha mãe, Isabel, meu pai, Carlos, minha irmã, Débora e minha avó, Mioco,por serem a fonte inesgotável de amor, carinho, suporte e perseverança desde o momento que nasci. Agradeço não apenas por toda a ajuda, mas também por serem minha maior inspiração em como encarar as dificuldade da vida, sempre de forma correta e humilde.

À minha namorada Amanda, por ser não apenas minha namorada, mas também minha melhor amiga e companheira de quarto. As dificuldades diárias são sempre aliviadas quando estamos juntos, em momentos de alegria e felicidade.

Ao meu orientador Prof. Fernando de Queiroz Cunha, pela orientação e discussões científicas e me ensinar a valorizar a ciência.

Aos meu amigos de laboratório e departamento: Bruno, Rafaela, Guilherme, Kalil, Juliana, Leonardo, Mikhael, Thainá, Prots, Fernanda, Caju, Eduardo, Timna, Marcos, Camilla, Wagner, Braulio, Alexandre, David, Rafael, JP, Douglas, Renan, Maria, Ana, Ayda, Nathalia, Vanessa e vários outros. Seja em bancada ou em mesa de bar, o convívio sempre rendeu boas risadas e discussões científicas.

Aos técnicos do LID, Kátia, Serginho, Marquinhos, Diva e leda, pela ajuda na organização e limpeza do laboratório, além do agradável convívio.

À Ana Cristine, pelo ajuda e disposição em auxiliar toda atividade burocrática.

Às agências de fomento, Coordenação de Aperfeiçoamento Pessoal de Nível Superior (CAPES), Conselho Nacional de Desenvolvimento Tecnológico e Científico (CNPQ), Fundação de Amparo à Pesquisa do Estado de São Paulo (FAPESP) e ao Center for Research in Inflammatory Diseases (CRID) pelo apoio financeiro fundamental para desenvolvimento deste trabalho. 


\section{LISTA DE FIGURAS}

Fig. 1. Distribuição das linhagens de Chikungunya pelos continentes..............14

Fig. 2. Visão geral sobre a NETose

Fig. 3. O vírus Chikungunya, mas não Dengue e Zika, é capaz de induzir a produção de NETs em neutrófilos murinos.

Fig. 4. A liberação de NETs induzida por Chikungunya é dependente do receptor intracelular Toll-Like 7

Fig. 5. A liberação de NETs induzida por Chikungunya é dependente de produção de espécies reativas de oxigênio.

Fig. 6. NETs são capazes de capturar e neutralizar o vírus Chikungunya

Fig. 7. Camundongos infectados com Chikungunya tratados com rhDNAse para degradar as NETs sistêmicas apresentam maior carga viral no sangue e são mais suscetíveis à infecção. 49

Fig. 8. O vírus Chikungunya, mas não Dengue e Zika, é capaz de induzir a liberação de NETs em neutrófilos. . .50

Fig. 9. NETs estão aumentadas no soro de pacientes infectados com Chikungunya e estão correlacionadas com maior carga viral 


\section{RESUMO}

HIROKI, CH. Papel das Neutrophil Extracellular Traps no controle da infecção por Chikungunya. Dissertação de mestrado. Faculdade de Medicina de Ribeirão Preto, Universidade de São Paulo, Ribeirão Preto, SP, Brasil, 2018, 73f,

O Chikungunya é um vírus reemergente que causa uma doença caracterizada por uma artralgia incapacitante que afeta milhares de pessoas. A resposta inata contra este vírus é bem descrita pela participação de macrófagos, células dendríticas e células NK, porém há poucos trabalhos que demonstram o papel dos neutrófilos nesta infecção. As Neutrophil Extracellular Traps (NETs) constituem uma rede de DNA complexada a enzimas antimicrobianas que foram descritas por combaterem diversos patógenos. Porém, não há trabalhos que demonstram sua importância em infecção por Chikungunya. Nosso objetivo foi investigar se há produção de NETs na infecção por Chikungunya, descrever seus mecanismos e demonstrar sua importância in vitro e in vivo. Observamos que neutrófilos murinos e humanos incubados com Chikungunya são capazes de produzir NETs via Toll-Like 7 e produção de espécies reativas de oxigênio. Estas NETs foram capazes de capturar o vírus e impedir sua infecção in vitro. Mais além, animais infectados com Chikungunya e tratados com rhDNAse apresentam maior carga viral e são mais suscetíveis à infecção, demonstrando sua importância in vivo. Por fim, pacientes diagnosticados em fase aguda de infecção por Chikungunya possuem elevados níveis de NETs correlacionados com uma alta carga viral.

O presente trabalho foi realizado com apoio do CNPq, Conselho Nacional de Desenvolvimento Científico e Tecnológico - Brasil

Palavras chaves: Chikungunya, NETs, neutrófilos. 


\section{ABSTRACT}

HIROKI, CH. Role of Neutrophil Extracellular Traps on the control of Chikungunya infection. Masters dissertation. Faculty of Medicine of Ribeirão Preto, University of São Paulo, Riberião Preto, SP, 2018, 73 f.

Chikungunya is a reemerging virus which causes a disease characterized by an incapacitanting arthralgia and affects thousands of people. Innate response against this virus is well described by participation of macrophages, dendritic cells and NK cells, however few works demonstrate the roe of neutrophils in this infection. Neutrophils Extracellular Traps are a web of DNA complexed with antimicrobial enzymes which were described for fighting against many pathogens. However, there are no works which demonstrate its relevance in Chikungunya infection. Our objective was to evaluate if there is release of NETs in Chikungunya infection, describe its mechanisms and demonstrate its relevance in vitro and in vivo. We observed that mouse and human neutrophils incubated with Chikungunya are able to produce NETs via Toll-Like 7 and reactive oxygen species production. These NETs were able to capture the virus and inhibit its infection in vitro. Moreover, animals infected with Chikungunya virus and treated with rhDNAse demonstrated higher viral load and are more susceptible to the infection, showing its importance in vivo. Lastly, patients diagnosed during acute infection of Chikungunya infection have high levels of NETs correlated with a high viral load.

This study was financed in part by the Conselho Nacional de Desenvolvimento Científico e Tecnológico (CNPq) - Brasil

Key words: Chikungunya, NETs, neutrophils. 


\section{SUMÁRIO}

1. INTRODUÇÃO

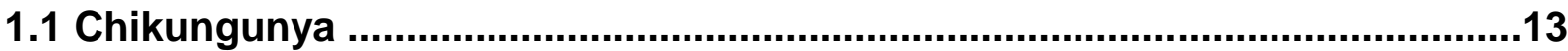

1.2 Resposta Imunológica contra Chikungunya.................................................18

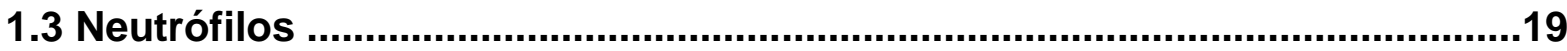

1.4 NETs

1.5 NETs e vírus

2. HIPÓTESE

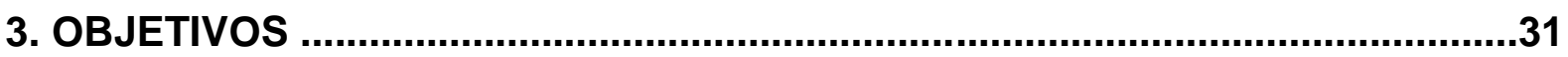

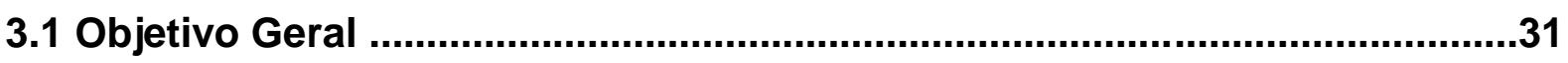

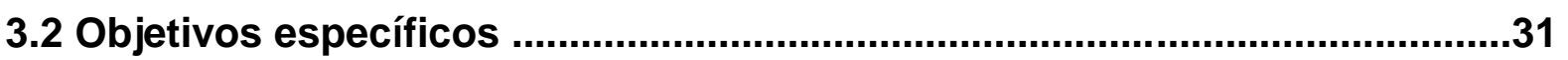

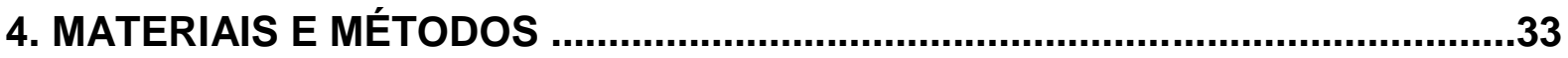

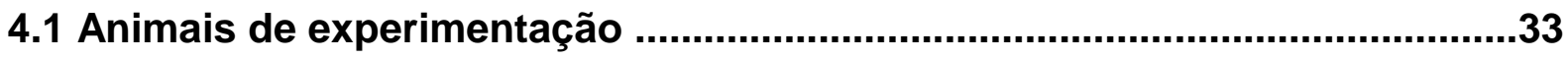

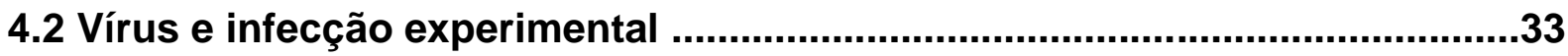

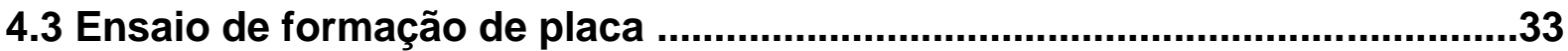

4.4 Isolamento de neutrófilo murino …..................................................................34

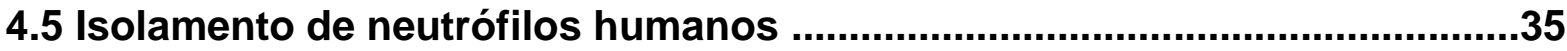

4.6 Imunofluorescência para NETs ........................................................................35

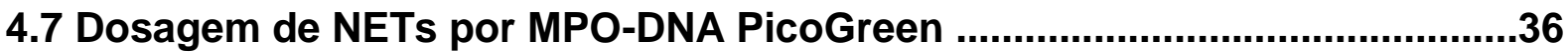

4.8 Imunofluorescência para internalização viral .................................................36 
4.9 Detecção de produção de espécies reativas de oxigênio

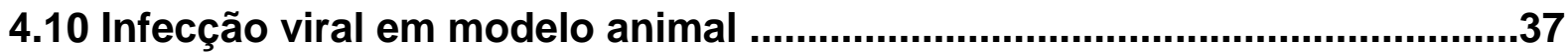

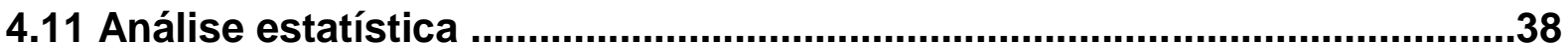

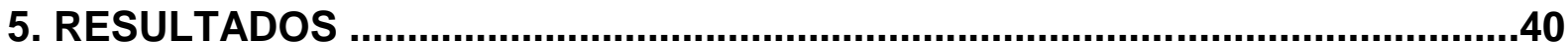

5.1 Neutrófilos murinos produzem NETs quando incubados com Chikungunya, mas não com Zika ou Dengue ..............................................................................40

5.2 A indução de NETose induzida por Chikungunya é dependente do receptor Toll-Like 7

5.3 O vírus Chikungunya induz uma NETose dependente de espécies reativas de oxigênio .43

5.40 vírus Chikungunya é capturado e neutralizado pelas NETs 45

5.5 Camundongos infectados com Chikungunya tratados com rhDNAse para degradar as NETs sistêmicas apresentam maior carga viral no sangue e são mais suscetíveis à infecção

5.6 NETs são liberadas em neutrófilos humanos incubados com Chikungunya, mas não com Zika e Dengue

5.7 Pacientes infectados com Chikungunya apresentam maiores níveis de NETs relacionados com um aumento na carga viral .50

6. DISCUSSÃO .53

7. CONCLUSÃO .60

8. REFERÊNCIAS 
INTRODUÇÃO 


\section{Introdução}

\subsection{Chikungunya}

O Chikungunya é um vírus do gênero Alphavírus pertencente à família Togaviridae e sua transmissão é feita por mosquitos da família Aedes. Nas últimas décadas, este vírus reemergente ganhou destaque por ter se tornado epidêmico em diversos países e por causar uma artralgia incapacitante, cujos mecanismos ainda não estão elucidados (Amdekar et al., 2017).

Antes do vírus Chikungunya ser isolado pela primeira vez na década de 50 a partir do soro de um paciente do leste africano, os casos de infecção eram confundidos com os casos de dengue devido às similaridades sintomática, com exceção de uma forte dor articular (Lumsdem, 1955). A palavra "Chikungunya" refere-se a "aquele que se curva" na língua tanzaniana, local em que houve um surto em 1952-1953, e está associada à dor que os pacientes infectados manifestavam nas articulações (Robinson, 1955).

Após sua descoberta, os relatos de infecções por Chikungunya eram notificados isoladamente nas regiões da Ásia e África, mas no início dos anos 2000 observou-se um aumento acentuado no número de casos nas regiões endêmicas e surtos inéditos em locais próximos (Lam et al., 2001). Este aumento vem sendo atribuído a fatores como globalização, adaptação do vírus em novos vetores, aumento na população de mosquitos, entre outros (Thiboutot et al., 2010). Atualmente, estes fatores levaram a notificações de pacientes infectados por este vírus em todos os continentes (WHO, 2018). 
Análises genéticas permitiram a distinção de três linhagens que diferem entre si pela sequência genética do envelope E1 e sua identificação é com base no local que foi descrito: a linhagem asiática, linhagem do oeste africano e a linhagem do leste-centro-sul africano. Em 2005, um surto que se espalhou do Quênia até a Índia e que foi provocado pela linhagem leste-centro-sul africana resultou em aproximadamente 1.5 milhão de indivíduos infectados. Uma mutação no gene do envelope (E1-A226V) possibilitou que o vírus infectasse e prolifera-se melhor no mosquito Aedes Albopictus, fato este que contribuiu para a magnitude do surto (Burt et al., 2017).

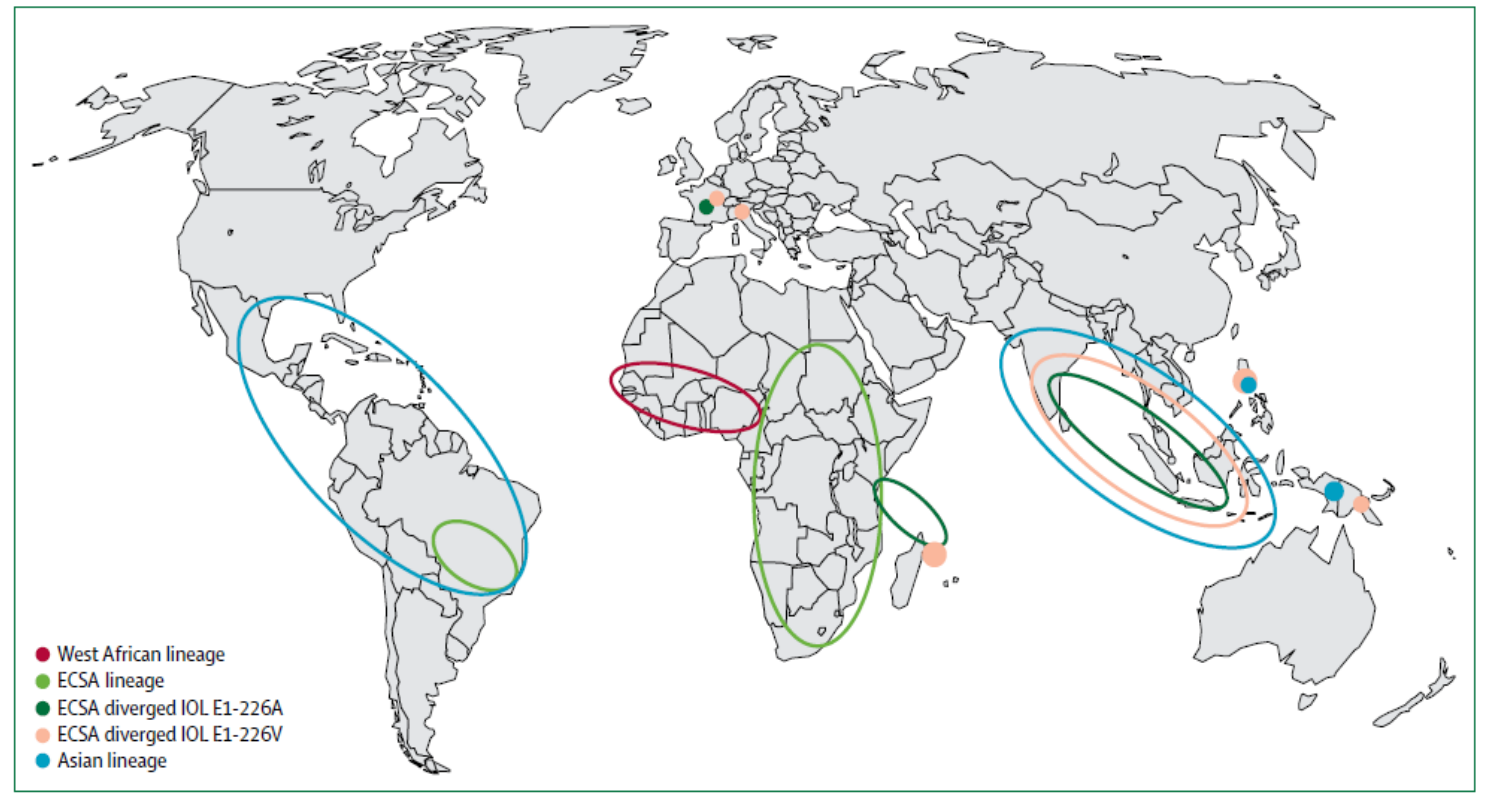

Fig. 1. Distribuição das linhagens de Chikungunya pelos continentes. Linhagens do oeste africano (do inglês West African), asiática (do inglês Asian) e do leste-centro-sul africano (ECSA, do inglês EastCentral-South African), com suas mutações. Adaptado de Burt et al. (2017).

No Brasil, os primeiros casos de infecção por Chikungunya foram notificados no segundo semestre de 2014, nas regiões do Amapá e da Bahia. Curiosamente, as linhagens identificadas nessas regiões eram distintas: a que ocorreu no Amapá foi 
identificada como a linhagem asiática, enquanto que a encontrada na Bahia foi a do leste-centro-sul africana (Nunes et al., 2015). No ano seguinte, foram notificados 20.598 casos, mas em 2016 houve um aumento drástico nesse número para 230.410, em todo o território brasileiro. Em 2017, foram relatados aproximadamente 131.749 casos de infecção por Chikungunya, resultando em 63,9 casos para cada 100 mil habitantes (Ministério da Saúde, 2018).

A transmissão desse vírus é feita através de vetores artrópodes como os mosquitos da família Aedes, como o Aedes aegypti e Aedes albopictus. Este vetor é também responsável pela transmissão de outros vírus, como Zika e Dengue. Apenas as fêmeas são capazes de disseminar o vírus ao picarem o hospedeiro durante o processo de hematofagia, apesar de estudos demonstrarem que os machos transmitir o vírus para as fêmeas durante o processo de acasalamento (Mavale et al., 2010). Um fato relevante é que o aumento no número de casos de infecção por Chikungunya geralmente coincide com períodos chuvosos que são associados ao aumento na população de mosquitos transmissores (Powers et al., 2007).

O ciclo inicia-se com o vetor adquirindo o vírus ao picar um indivíduo infectado para obtenção de sangue. Logo, o vírus infecta e prolifera-se nas células epiteliais mesenquimais do vetor e dissemina-se para as glândulas salivares, fato este que permite a transmissão para um novo hospedeiro (Lounibos et al., 2016). Este ciclo de incubação, que dura em torno de dias, permite que o mosquito seja capaz de transmitir o vírus por toda a sua vida (Vega-Rúa et al., 2014).

Após inoculação intradérmica, o Chikungunya adentra os capilares subcutâneos, onde inicia o processo de proliferação nas células permissíveis à infecção, como macrófagos, fibroblastos e células endoteliais (Palha et al., 2013). É 
descrito que a saliva do Aedes aegypti possui propriedades anticoagulantes e antiinflamatórias que auxiliam na proliferação do Chikungunya na derme, inibindo a resposta antiviral local (Wichit et al., 2017). Apesar da resposta imune iniciar poucas horas após a infecção, o vírus pode sobrepor a resposta e alcançar a corrente sanguínea (Couderc et al., 2008). Durante este período de incubação que leva de 3 a 7 dias, observa-se um aumento substancial da carga viral em diversos órgãos, como linfonodos, fígado, rins e articulações, e que pode chegar à titulação de $10^{10}$ cópias/mL no plasma (Chow et al, 2011). Nesta fase, o diagnóstico pode ser feito com base na detecção viral pela técnica de RT-PCR e/ou pela identificação de anticorpos da classe IgM (Dupuis-Maguiraga et al., 2012).

$\mathrm{Na}$ maioria dos casos, os sintomas da fase aguda consistem de febre, cansaço, dor nas articulações, mialgia e perduram por três semanas. Porém aproximadamente $15 \%$ dos pacientes apresentam uma forte artralgia persistente que se assemelha a um quadro de artrite reumatoide e que pode estender por meses ou mesmo anos decorrente da persistência viral nas articulações (Zaid., 2018). A causa da persistência desse sintoma ainda não foi elucidada, sendo um dos motivos a ausência de um modelo experimental de infecção viral crônica que inviabiliza a investigação desse mecanismo (Chow et al., 2011).

O Chikungunya consiste de uma fita simples de RNA, de carga positiva e com um tamanho molecular de aproximadamente 12kb. Este genoma é formado por uma extremidade 5' contendo uma região 7-metilguanosina não traduzida, seguida de quatro genes não estruturais (nsP1-4), cinco genes estruturais (C, E1, E2, E3 e 6K) e uma extremidade 3' contendo uma cauda poliadenilada. As regiões estruturais e não estruturais possuem sequências promotoras, o que permite a expressão 
concomitante desses genes durante a infecção celular (Rashad et al., 2014). Este conteúdo é armazenado dentro de um capsídeo icosaédrico, envolto por um envelope lipídico oriundo da membrana plasmática da célula hospedeira, medindo cerca de 60-70nm (Rougeron et al., 2015).

Vírus do gênero Alphavírus são descritos por serem capazes de infectar uma variedade de tipos celulares, como células epiteliais, endoteliais, fibroblastos, e algumas de linhagem mieloide (Sourisseau et al., 2007) sendo que a infecção na célula-alvo é mediada pelo processo de endocitose. Recentemente, descobriu-se que o Chikungunya utiliza a molécula MXRA8 (do inglês Matrix Remodeling Associated 8) para infectar a célula (Zhang et al., 2018). Quando no interior da célula, a acidificação endossomal permite a fusão do envelope com a membrana plasmática, resultando na liberação do capsídeo para o citoplasma e subsequente liberação do RNA viral para o citoplasma (Bernard et al., 2010). Nesta etapa, os genes não estruturais são traduzidos para a geração de um complexo proteico de replicação que utiliza o próprio RNA viral para gerar outro RNA de carga negativa, que servirá de molde para a síntese dos RNAs subgenômico e genômico (Salonen et al., 2004).

O RNA subgenômico é responsável pela expressão das proteínas estruturais, gerando o capsídeo e o complexo proteico pE2-6K-E1. Este último é transportado para o retículo endoplasmático e, posteriormente, para o complexo de Golgi na qual ocorre o término do processamento e maturação. Logo, o complexo é transportado para a membrana plasmática, onde o pE2 é clivada por uma protease, gerando os componentes E2 e E3. Concomitantemente, o capsídeo interage com o RNA genômico, envolvendo-o e formando o nucleocapsídeo, que por sua vez, migra para 
a região da membrana plasmática contendo as proteínas sintetizadas e para formação do envelope, terminando o ciclo viral (Na et al., 2017). Durante esse ciclo, receptores intracelulares presentes na célula infectada podem reconhecer o vírus e desencadear uma resposta imune anti-viral.

\subsection{Resposta imunológica contra Chikungunya}

A resposta imunológica contra o Chikungunya inicia logo após a inoculação intradérmica realizada pelo vetor, na qual o vírus começa a proliferar e infectar células residentes como queratinócitos, melanócitos, macrófagos e fibroblastos. Todavia, essas células também são capazes de reconhecer o vírus em seu citoplasma por receptores de resposta inata, como os receptores Toll-Like (TLR) 3, 7 ou 8, RIG-I (do inglês Retinoic Acid-inducible Gene I), MDA5 (do inglês Melanoma Differentiation-Associated-protein 5), que induzem a expressão de moléculas com atividade antiviral, que são responsáveis pela inibição da proliferação do vírus (Gasque et al., 2015). Dentre as moléculas produzidas, destaca-se o papel dos Interferon (IFN) do tipo I no combate ao Chikungunya, na qual animais deficientes para seu receptor são extremamente suscetíveis à infecção (Couderc et al., 2008).

Além disso, as células residentes ativadas produzem outras citocinas com propriedade inflamatórias, como o TNF-a (do inglês Tumor Necrosis Factor Alpha) e a interleucina (IL)-6, e também quimiocinas, como IL-8, que recrutam e ativam células, criando um ambiente pró-inflamatório. Em poucas horas ocorre a migração de macrófagos, células dendríticas e células NK (do inglês Natural Killer), que podem (i) internalizar o vírus e eliminá-lo, (ii) reconhecer e levar a apoptose células infectadas para eliminar reservatórios virais, (iii) produzir mais citocinas e 
quimiocinas para potencializar a resposta e (iv) apresentar antígenos virais para linfócitos (Burt et al., 2017).

O papel dos monócitos, células dendríticas e células NK são mais descritos no controle da infecção inicial por Chikungunya, no entanto o papel de neutrófilos na resposta antiviral ainda não foi completamente elucidado, embora estas células sejam recrutadas para o foco infeccioso (Amdekar et al., 2017).

\subsection{Neutrófilos}

Os Neutrófilos constituem a maioria das células imune presentes no sangue periférico $(50-70 \%)$ sendo as primeiras a serem recrutadas no foco inflamatório, onde são responsáveis pelo combate inicial ao patógeno. Esta célula é derivada de mieloblastos, sendo gerada pelo processo de hematopoiese na medula óssea e ao final da maturação, a mesma deixa o local com seu fenótipo de núcleo polimorfonuclear e grânulos acumulados em seu citoplasma (Carvalho et al., 2015).

Durante uma infecção, o recrutamento dos neutrófilos circulantes ocorre em distintas etapas, sendo mediado pela produção de fatores quimiotáticos no foco inflamatório, como IL-8, que são capazes de se ligar aos seus receptores, como o CXCR1. Uma vez no local de inflamação, esta célula possui diversos mecanismos para combater os patógenos, como fagocitose, produção de radicais livres e liberação de proteases (Fattori et al., 2016).

Apesar de possuírem curto período de vida (6h-12h), os neutrófilos possuem um importante papel na resposta às infecções, uma vez que pacientes com neutropenia apresentam maior suscetibilidade à infecções, como a sepse (Reilly et al., 2016).A 
depleção destas células em modelos animais, utilizando anticorpos específicos antiGr1 ou anti-Ly6G, torna estes animais mais suscetíveis a serem infectados por uma diversidade de patógenos, como bactérias, fungos, protozoários e até mesmo vírus (Egan et al., 2008). Apesar de suas funções microbicidas terem sido descritas principalmente em bactérias, o papel dos neutrófilos em infecções virais continua pouco explorado (Gabriel et al., 2013).

Como já demonstrado que em determinadas infecções virais, como vírus sincicial respiratório, herpes e influenza, os neutrófilos constituem a maioria do infiltrado celular no foco infeccioso, devido à alta produção de fatores quimiotáticos para esta célula (Smith et al., 2001; Wojtasiak et al., 2010; Perrone et al., 2008). Uma vez no local, o neutrófilo é capaz de reconhecer os vírus através de receptores de reconhecimento padrão, como os receptores Toll-Like, e desencadear uma resposta imune com a finalidade de eliminá-los. Dentre os mecanismos desencadeados, os mais conhecidos são a degranulação e a produção de espécies reativas de oxigênio. Na degranulação ocorre a liberação do conteúdo neutrofílico armazenado em grânulos, como as a-defensinas, que possuem propriedades antivirais. Por outro lado, a produção de espécies reativas de oxigênio (também chamado de burst oxidativo) ocorre através da ativação do complexo multienzimático NADPH oxidase, que resulta na geração de espécies reativas, como o superóxido e a $\mathrm{H}_{2} \mathrm{O}_{2}$, que são capazes de oxidar o RNA viral (Gabriel et al., 2013). Mais além, a produção de espécies reativas foi descrita por estar envolvida com outro mecanismo microbicida dos neutrófilos: as Neutrophil Extracellular Traps.

\subsection{NETs}


As Neutrophil Extracellular Traps (NETs) são estruturas extracelulares constituída de DNA e diversas enzimas antimicrobianas, como mieloperoxidase, elastase, catepsina G e LL-37. Descritas inicialmente em 2004 por Brinkmann et al, esta estrutura foi descrita por ser liberada durante uma infecção bacteriana e ser capaz de capturar e eliminar o patógeno, impedindo sua proliferação (Brinkmann et al., 2004). Desde então, diversos patógenos foram descritos por induzirem e serem combatidos por este mecanismo, como fungos, protozoários e vírus (Papayannopoulos et al., 2017). Foi demonstrado que animais deficientes em NETs são mais suscetíveis à infecção, ressaltando sua importância no contexto infeccioso (Li et al., 2010).

O processo de formação de NETs, denominado NETose envolve diversas vias de sinalização e dependendo do estímulo inicial, pode ser dividido em NETose suicida ou vital, que pode resultar na morte ou na sobrevivência da célula, respectivamente (Fig. 2). Estímulos como phorbol-12-myristate-13-acetate (PMA) e cristais de colesterol induzem a via suicida através da ativação da enzima NADPHOxidase, que como mencionado anteriormente, é responsável pela produção de espécies reativas de oxigênio. Estes radicais são responsáveis por dois importantes fatores para a NETose: (i) ativação da enzima protein-arginine deiminase 4 (PAD4), que tem um papel importante no sequestro um grupamento amino do aminoácido arginina, convertendo-o a citrulina, nas histonas $\mathrm{H} 3$ e $\mathrm{H} 4$, provocando a descondensação do DNA; e (ii) dissociação de grânulos azurofílicos, com a liberação das enzimas elastase e mieloperoxidase, que são transportadas para o núcleo, onde agregam-se ao DNA. Na sequência, ocorre rompimento da membrana nuclear e interação do DNA com as enzimas citoplasmáticas, seguida de lise da membrana plasmática e liberação das NETs (Papayannopoulos et al., 2010; Li et al., 
2010). Vale a pena comentar que recentemente foi descrito que o rompimento da membrana plasmática é mediado pela enzima Gasdermina D, cuja ativação é dependente da clivagem por elastase (Sollberger et al., 2018).

Por outro lado, a via vital é descrita por não ter rompimento da membrana celular e o neutrófilo ainda é capaz de executar funções como fagocitose e quimiotaxia. Esta via, responsiva a estímulos de infecções por bactérias, fungos ou plaquetas ativadas, pode ocorrer na ausência de espécies reativas de oxigênio, na qual o DNA é então liberado em vesículas (Byrd et al., 2013; Yipp et al., 2012).

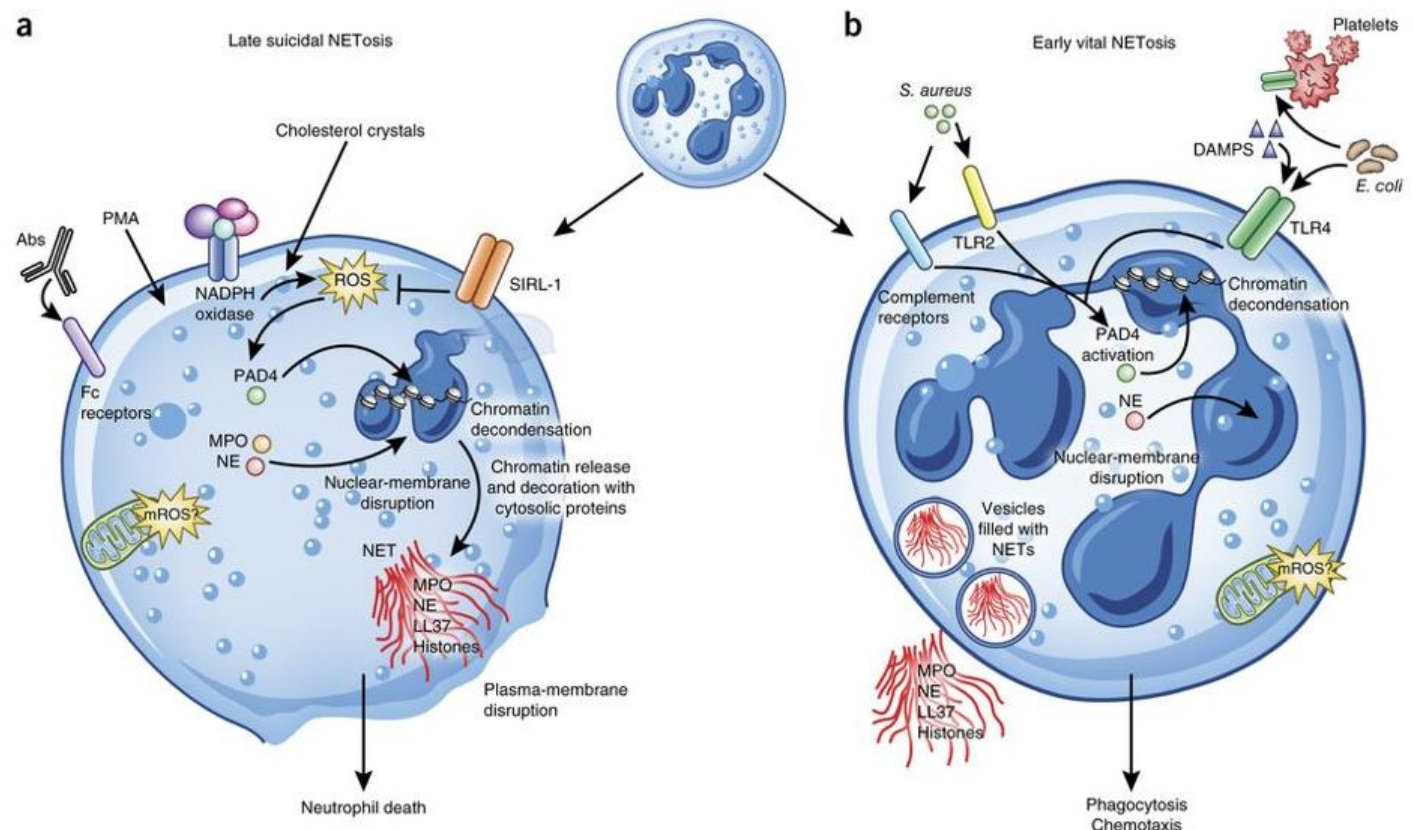

Fig. 2. Visão geral sobre a NETose. (a) Diferentes estímulos como PMA, anticorpos ou cristais de colesterol induzem a NETose suicida, que ocorre horas após o estímulo. Após ativação da NADPH oxidase, espécies reativas de oxigênio são produzidas e a enzima PAD4 é ativada, o que resulta em descondensação da cromatina. Em seguida, elastase e mieloperoxidase são translocadas para o núcleo para promover desdobramento da cromatina, com rompimento da membrana nuclear. A cromatina é liberada no citoplasma, onde associa-se a proteínas citosólicas e granulares. Finalmente, NETs são liberadas por rompimento da membrana plasmática e a célula morre. (b) A NETose vital é induzida em minutos por $S$. aureus pelo receptor de complemento e receptor Tol-Like 2, ou por E.coli ligando diretamente no receptor Tol-Like 4 ou por ativação de plaqueta. A enzima PAD4 é ativada, porém sem produção de espécies reativas de oxigênio e induz a descondensação da cromatina. Assim como na NETose suicida, a elastase é translocada para o núcleo para promover desdobramento da cromatina e disrupção da membrana nuclear. Contudo, a cromatina complexada a proteínas é expelida por vesículas e o neutrófilo continua vivo para exercer funções, como fagocitose. Como as espécies reativas de 
oxigênio estão envolvidas em uma via ou outra na NETose ainda não está bem estabelecido. Adaptado de Jorch et al. (2017).

Quando liberadas no meio extracelular, as NETs são capazes de interagir com os patógenos por interação eletrostática entre os componentes de carga positiva da parede bacteriana com aqueles de carga negativa, coma a cromatina, aprisionando-os. Deste modo, inibe-se a migração destes patógenos pelo tecido e sua interação com outros órgãos (Brinkmann et al., 2007). Além disso, as enzimas presentes nas NETs possuem atividades antimicrobicidas, como a mieloperoxidase, responsável pela geração do agente microbicida ácido hipocloroso, elastase, que rompe membrana bacteriana, e a lisozima, que inibe bactérias gram positivas (Azzaq Belaaouaj et al., 2000; Aratani et al., 2018; Pu et al., 2016).

Outros trabalhos apresentam que determinados patógenos possuem mecanismos de evasão das NETs, como as bactérias $S$. aureus e $S$. pneumoniae, que expressam DNAse que degradam as NETs e provocar proliferação e disseminação bacteriana (Beiter et al., 2006; Berends et al., 2010). Outras, como Streptococcus, são capazes de alterar suas estruturas de superfícies, reduzindo sua interação com as NETs (Carlin et al., 2009).

Por outro lado, apesar de seu papel protetor relatado durante infecções, as NETs podem ser também responsáveis pela indução de lesão tecidual, uma vez que seus componentes podem não apresentar especificidade apenas pelos patógenos e interagir com diferentes órgãos, danificando-os. Na patofisiologia de doenças autoimunes e inflamatórias, as NETs são produzidas cronicamente e em grandes quantidades, sendo associada aos danos celulares (Bonaventura et al., 2018). Nosso grupo demonstrou que pacientes sépticos possuem elevados níveis de NETs 
circulantes que está associado a lesão de diferentes órgãos vitais e na formação de trombos (McDonald et al., 2017; Czaikoski et al., 2016).

Desde sua descoberta, a maioria dos trabalhos tem associado as NETs com infecções bacterianas e fúngicas. Porém, recentes trabalhos vêm associando cada vez mais este mecanismo de defesa com determinadas infecções virais (AgrazCibrian et al., 2017).

\subsection{NETs e vírus}

Diversos trabalhos vêm demonstrando que vírus são capazes de induzir a liberação de NETs através de diferentes vias que dependem do receptor envolvido na sinalização. Neutrófilos são capazes de reconhecer o vírus HIV pelo receptor endossomal Toll-Like 7 e 8, desencadeando uma NETose dependente de espécies reativas de oxigênio (Saitoh et al., 2012). Adicionalmente, outros grupos descreveram que receptores localizados na porção extracelular da membrana plasmática também são capazes de iniciar o processo de NETose. Por exemplo, a proteína viral F do vírus sincicial respiratório é reconhecido pelo receptor Toll-Like 4, iniciando uma sinalização via p38-MAPK que resulta na liberação de NETs (Funchal et al, 2015). Por outro lado, o Hantavírus é capaz de iniciar a NETose através do receptor de integrinas $\beta 2$, ativando a via dependente de NADPH-Oxidase (Raftery et al., 2014).

Em adição, diferentes grupos tem sugerido que o ambiente inflamatório ocasionado pela infecção viral é capaz de ativar os neutrófilos a liberarem NETs. Foi demonstrado que o vírus da Dengue é capaz de infectar células endoteliais, as quais 
respondem com a produção de IL-8, que já descrita por induzir NETose (Huang et al., 2000; Gupta et al., 2010). Além disso, a principal classe de citocinas produzidas durante uma infecção viral são os IFN-I, que são capazes de pré-ativar os neutrófilos, tornando-os mais sensíveis a NETose (Martinelli et al., 2004).

Apesar de diversos estudos demonstrarem que vírus são capazes de induzir a produção de NETs, pouco foi explorado o mecanismo efetor destas contra estes patógenos. De uma forma direta, foi proposto que as NETs são capazes de capturar os vírus por atração eletrostática e impedir sua infecção e proliferação. Estudos demonstraram que o vírus HIV perde parcialmente sua infectividade em linfócitos e no trato vaginal quando pré-incubados com NETs (Saitoh et al., 2012; Barr et al., 2018). De forma semelhante, o vírus sincicial respiratório também tem sua capacidade de infecção reduzida quando incubados previamente com NETs (Souza et al., 2018). Concomitantemente, as enzimas presentes nas NETs, como a mieloperoxidase, catelicidinas e a-defensinas, apresentam relevante capacidade antiviral, tanto contra os vírus envelopados e os não-envelopados (Findlay et al., 2013). De forma indireta, foi demonstrado que as NETs podem induzir a expressão de IFN-I por células dendríticas plasmocitóides via receptor Toll-Like 9 (Garcia-Romo et al., 2011),.

Por outro lado, diversos vírus são descritos por possuírem mecanismos adaptado de evasão da resposta imune, incluindo as NETs. Como já citado anteriormente, o vírus HIV é capaz tanto de induzir a NETose, como também a indução de IL-10 pelas células dendríticas, inibindo a produção de espécies reativas de oxigênio em neutrófilos e consequentemente, inibindo a formação de NETs (Saitoh et al., 2012). Mais recentemente, outro estudo demonstrou que o vírus da 
Dengue inibe a produção de NETs ao interferir no processo de captação de glicose dos neutrófilos (Moreno-Altamirano et al., 2015).

Como já citado, as NETs podem ser responsáveis pela patofisiologia de doenças inflamatórias ou autoimunes. Mesmo com seu papel antiviral descrito, diversos trabalhos vêm apontando que as NETs, em determinadas situações, podem contribuir também para o processo patológico das infecções virais. Por exemplo, um recente estudo demonstrou que pacientes infectados com vírus sincicial respiratório apresentam uma excessiva formação de NETs nas vias respiratórias, levando à quadro inflamatório que pode resultar em sua oclusão (Cortjens et al., 2016). Outro estudo demonstrou que a liberação de NETs em pacientes com Hantavírus induz a produção de autoanticorpos contra DNA dupla fita e histonas, levando a um quadro similar ao Lúpus Eritematoso Sistêmico (Raftery et al., 2014). Finalmente, em outro estudo, apesar do mecanismo não ter sido descrito, foi demonstrado que elevados níveis de NETs no plasma de pacientes infectados com vírus Influenza A esta correlacionado com pior prognóstico devido a lesão pulmonar (Zhu et al., 2018).

$\mathrm{Na}$ literatura não há relatos de estudos com NETs e Chikungunya, porém sabe-se neutrófilos podem possuir um papel em sua infecção. Em modelo de peixe zebra infectado com Chikungunya, sabe-se que o neutrófilo, em conjunto com hepatócitos, são as principais células produtoras de IFN do tipo I (Palha et al., 2013). Em modelos murinos, esta célula é recrutada no foco infeccioso, porém seu papel no local ainda não foi elucidado (Dhanwani et al., 2014).

Deste modo, uma vez que neutrófilos são recrutados durante uma infecção por Chikungunya em modelos experimentais, mas sua função não está esclarecida, 
nosso objetivo foi investigar se esta célula é capaz de produzir NETs e avaliar ainda o seu papel no mecanismo imune responsável pela resposta anti-viral. 
HIPÓTESE 


\section{HIPÓTESE}

A infecção por Chikungunya afeta milhares de pessoas por ano gerando comprometimento da qualidade de vida devido aos sintomas ocasionados. Neste contexto, compreender a fisiopatologia desta doença é fundamental para o desenvolvimento de tratamentos eficazes que levem a cura dos pacientes. Nossa hipótese é de que os neutrófilos sejam ativados por este vírus e produzam NETs, que são responsáveis pelo controle da infecção. 
OBJETIVOS 


\section{OBJETIVOS}

\subsection{Objetivo Geral}

- Caracterizar o papel das NETs na infecção por Chikungunya

\subsection{Objetivos específicos}

- Demonstrar se há produção de NETs em neutrófilos murinos e humanos incubados com Chikungunya

- Avaliar os mecanismos que induzem a NETose ativada por Chikungunya

- Avaliar a relevância das NETs durante infecção por Chikungunya in vitro e in vivo

- Avaliar a produção de NETs em pacientes infectados com Chikungunya 


\section{MATERIAIS E MÉTODOS}




\section{MATERIAIS E MÉTODOS}

\subsection{Animais de experimentação}

Foram utilizados animais tipo-selvagem C57BL/6 e 129 SVEV, camundongos geneticamente modificados deficientes de IFNAR (IFNAR KO), TLR3 (TLR3 KO), TLR3/7/9 (TLR3/7/9 KO) e TLR9 (TLR9 KO), sendo machos, entre 6 a 9 semanas de idade. Os camundongos foram mantidos no biotério do Departamento de Farmacologia da Faculdade de Medicina de Ribeirão Preto em condições livres de patógenos específicos, ambiente com temperatura controlada $\left(22\right.$ a $\left.25^{\circ} \mathrm{C}\right)$ e receberam água a ração ad libidum. Os experimentos foram conduzidos de acordo com o Comitê de Ética em pesquisa animal (CETEA) da Faculdade de Medicina de Ribeirão Preto.

\subsection{Vírus e infecção experimental}

Foi utilizado vírus Chikungunya isolado da amostra de soro de um paciente atendido no hospital universitário da Universidade Federal de Pernambuco. O vírus foi sequenciado e associado ao genótipo de cepa asiática. O estoque viral foi mantido em células Vero, em meio DMEM (SigmaAldrich) high glucose, com $10 \%$ de soro fetal bovino, $1 \%$ de penicilina e streptamicina e 1\% de aminoácidos não essenciais

\subsection{Ensaio de formação de placa}


Para avaliação de carga viral, foi utilizado o método de formação de placa. Para isso, foram utilizadas células Vero (fibroblastos de rim de macaco verde africano) que foram cultivadas em garrafas de cultura estéreis, em meio DMEM (Sigma-Aldrich) high glucose, com 10\% de soro fetal bovino, $1 \%$ de penicilina e streptamicina e $1 \%$ de aminoácidos não essenciais. As células foram tripsinizadas e plaqueadas em placas de 24 poços na quantidade de $3.10^{5}$ células por poço e deixadas overnight para aderência. Logo, as células foram lavadas com solução de PBS para retirada do soro e incubadas com uma diluição seriada do vírus em meio DMEM em estufa, por uma hora, a $37^{\circ} \mathrm{C}$ e $5 \%$ de $\mathrm{CO} 2$, sendo completado com uma solução de meio DMEM, com $2 \%$ de carboximetilcelulose, até $0.5 \mathrm{~mL}$ e mantidas em estufa por dois dias. Após esse período, o meio foi aspirado e as células foram fixadas com paraformaldeído 4\% por meia hora. Após a retirada do paraformaldeído e lavagem com solução de PBS, as células foram incubadas com solução cristal violeta $2 \%$ por meia hora e foi feita a contagem da formação das placas.

\subsection{Isolamento de neutrófilo murino}

Foi obtida a medula óssea de fêmures e tíbias de camundongos C57BL/6, 129 SVEV, IFNAR KO, TLR3 KO, TLR3/7/9 KO e TLR9 KO em meio Hanks (Sigma-Aldrich). As amostras foram cuidadosamente pipetadas em um gradiente de Percoll (GE HealthCare) de concentrações $72 \%$ e $65 \%$ e centrifugadas por 30 minutos, a 1200g, temperatura ambiente. Logo, as células polimorfonucleares foram separadas e lavadas com meio Hanks, ressuspendidas em meio RPMI-1640 suplementado com $0.1 \%$ de BSA (Sigma- 
Aldrich) e contadas em câmara de Neubauer. Para avaliação da pureza, foi feito um esfregaço das células e coradas com corante Panótico (Interlab) e avaliadas em microscópio.

\subsection{Isolamento de neutrófilos humanos}

Amostras de sangue periférico de indivíduos saudáveis foram obtidos em tubo contendo anticoagulante EDTA e pipetadas cuidadosamente em uma curva de Percoll (GE Healthcare) de concentrações 72\%, 63\%, 54\% e 45\% e centrifugadas por 30 minutos, a $650 \mathrm{~g}$, temperatura ambiente. Em seguida, as células polimorfonucleares foram isoladas, lavadas em meio Hanks, ressuspendidas em meio RPMI-1640 suplementado com $0.1 \%$ de BSA (X) e contadas em câmara de Neubauer. Para avaliação de pureza, foi utilizado o mesmo método descrito anteriormente.

\subsection{Imunofluorescência para NETs}

Lamínulas redondas de $13 \mathrm{~mm}$ (Glascito) foram incubadas com Poli-Llisina (Sigma-Aldrich) por 10 minutos, lavadas com solução de PBS e deixadas overnight para secar, em estufa de secagem. Após o isolamento de neutrófilos, as células foram incubadas por 30 minutos nas lamínulas para aderência e os estímulos incubados em seguida. Para controle negativo, foi utilizado meio RPMI-1640 suplementado com $0.1 \%$ de BSA. Os estímulos foram incubados com as células por 4 horas, a $37^{\circ}$ e $5 \%$ de CO2. Logo, o sobrenadante foi

retirado e as células foram lavadas com solução de PBS e incubadas com 
paraformaldeído $4 \%$ por meia hora. Em seguida, foi feito o bloqueio com solução de PBS contendo $2 \%$ de BSA, por duas horas, em temperatura ambiente. Após uma lavagem com solução de PBS, as lamínulas foram incubadas overnight, a $4^{\circ} \mathrm{C}$, com anticorpos anti-H3 citrulina (1:1000; Abcam), anti-Ly6G (1:50; Invitrogen) ou anti-Chikungunya (1:100), obtido do laboratório do Prof. Luiz Tadeu Moraes Figueiredo. Em seguida, as lamínulas foram lavadas e incubadas com anticorpos Alexa Fluor 488 anti-rabbit (1:1000; Invitrogen) e Alexa Fluor 594 anti-mouse (1:100; Invitrogen), por 2 horas, a temperatura ambiente. As amostras foram lavadas e montadas em lâminas com ProLong ${ }^{\mathrm{TM}}$ Gold Antifade Mountant with DAPI (Molecular Probes) e avaliadas em microscópio de fluorescência (Leica Microsystem).

\subsection{Dosagem de NETs por MPO-DNA PicoGreen}

Para avaliar a produção de NETs em sobrenadante ou em amostra de plasma murino ou humano, foi utilizado o método MPO-DNA PicoGreen. Brevemente, foi utilizado uma placa Black Plate Clear Bottom (Sigma-Aldrich) para realizar o coating com anticorpo anti-MPO (1:1000, ThermoFisher), overnight, a $4^{\circ} \mathrm{C}$. A placa foi lavada em solução de PBS-Tween $0.5 \%$ e incubadas com as amostras, overnight a $4^{\circ} \mathrm{C}$. Após a lavagem, é adicionado 0 reagente fluorescente Quant-iT ${ }^{\mathrm{TM}}$ PicoGreen ${ }^{\mathrm{TM}}$ dsDNA Assay Kit (Invitrogen), seguida de leitura dos dados no aparelho FlexStation ${ }^{\circledR}$ 3, com excitação a $488 \mathrm{~nm}$ e leitura a $525 \mathrm{~nm}$.

\subsection{Imunofluorescência para internalização viral}


Neutrófilos murinos foram isolados pelo protocolo já descrito e incubados com o vírus Chikungunya, em lamínulas previamente sensibilizadas com Poli-Llisina (Sigma-Aldrich). As amostras foram lavadas e fixadas com PFA 4\%. Logo, as amostras foram bloqueadas com PBS/BSA 2\% por duas horas, temperatura ambiente e incubadas com anticorpo anti-ChikV (1:100) e antiLy6G (1:50, Invitrogen), overnight, $4^{\circ} \mathrm{C}$. As lamínulas foram lavadas e incubadas com Alexa FLuor 488 anti-Rat (1:100, Invitrogen) e Alexa Fluor 594 594 anti-mouse (1:200, Invitrogen) por duas horas, temperatura ambiente. Em seguida, as amostras foram montadas utilizando ProLong ${ }^{\mathrm{TM}}$ Gold Antifade Mountant with DAPI (Molecular Probes) e avaliadas em microscópio de fluorescência (Leica Microsystem).

\subsection{Detecção de produção de espécies reativas de oxigênio}

Para detectar a produção de ROS, neutrófilos murinos foram isolados pelo método descrito anteriormente e incubados com os estímulos, a $37^{\circ} \mathrm{C} \mathrm{e}$ $5 \%$ de $\mathrm{CO} 2$, pelos períodos de meia, 1, 2 e 3 horas. Em seguida, as amostras foram incubadas com a sonda CM-H2DCFDA (Molecular Probes) por meia hora, a $37^{\circ} \mathrm{C}$ e $5 \%$ de $\mathrm{CO} 2$. Os dados foram adquiridos no citômetro FacsVerse (BD Bioscience) no comprimento de onde 492nm.

\subsection{Infecção viral em modelo animal}

Camundongos machos C57BL/6, 129 SVEV e IFNAR KO, entre 6 a 9 semanas de idade, foram infectados com $3.10^{1}$ PFU de vírus Chikungunya, via 
intraperitoneal. Os animais foram mantidos no biotério do Departamento de Virologia da Faculdade de Medicina de Ribeirão Preto, em ambiente com temperatura controlada $\left(22\right.$ a $\left.25^{\circ} \mathrm{C}\right)$ e receberam água a ração ad libidum. Para coleta das amostras, os animais foram eutanasiados com dose excessiva de anestésico (doses). O sangue foi coletado por punção cardíaca em eppendorfs contendo heparina e centrifugado para separação de plasma.

\subsection{Análise estatística}

Os resultados foram representados como média e seu respectivo desvio padrão (Média+SD). Para comparação entre múltiplos grupos, foi utilizada a análise de variância (two-way ANOVA ou one-way ANOVA), seguida pelo pósteste de Bonferroni. Diferenças nos valores entre dois grupos foram determinadas utilizando o teste $t$ de Student. Todas as análises foram feitas com o auxílio do software GraphPad-Prism (GraphPad Software Inc., San Diego CA, EUA). Foram consideradas estatisticamente diferentes as amostras com o valor mínimo de $p<0.05$. O experimento de correlação utilizou-se a correlação de sperman e considerados correlação $p<0.05$. 
RESULTADOS 


\section{RESULTADOS}

\subsection{Neutrófilos murinos produzem NETs quando incubados com Chikungunya, mas não com Zika ou Dengue}

Inicialmente, para determinar se o Chikungunya era capaz de induzir a produção de NETs, neutrófilos murinos foram isolados e incubados com 0 vírus, em diferentes $\mathrm{MOI}$ (do inglês, multiplicity of infection), por diferentes períodos de incubação. Para os $\mathrm{MOI}$, testamos as proporções 0.5 , 5 , e 50 , e os tempos de incubação foram de uma, duas, quatro e oito horas. Paralelamente, avaliamos se outros arbovírus, como Dengue e Zika, induziam a produção de NETs também. Curiosamente, observamos que o único vírus que induziu essa produção foi o Chikungunya, cuja melhor condição experimental foi em MOI de 5 e com quatro horas de incubação (Fig. 3A e Fig. 3B). Para confirmar nosso resultado se este vírus era o único capaz de induzir o neutrófilo a entrar em NETose, realizamos uma imunofluorescência para NETs. Corroborando com os dados anteriores, apenas o vírus Chikungunya foi capaz de induzir a geração (Fig. 3C). Deste modo, demonstramos que apenas o vírus Chikungunya foi capaz de induzir a produção de NETs. 
A

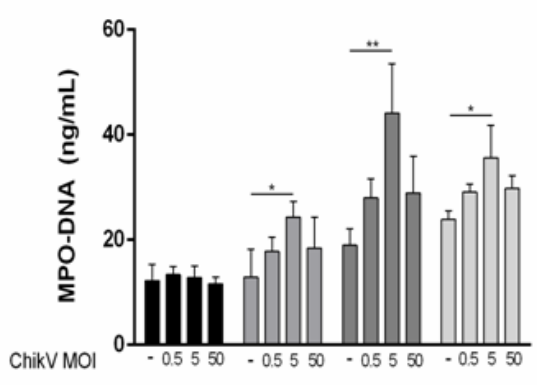

C

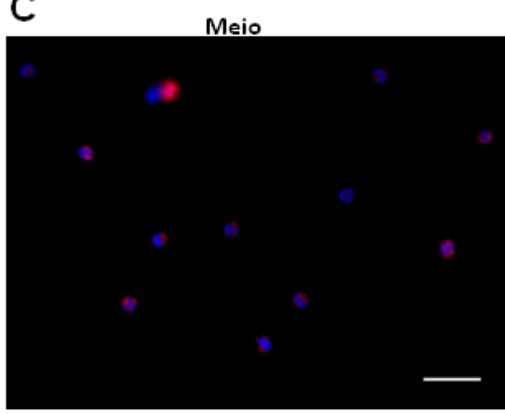

B
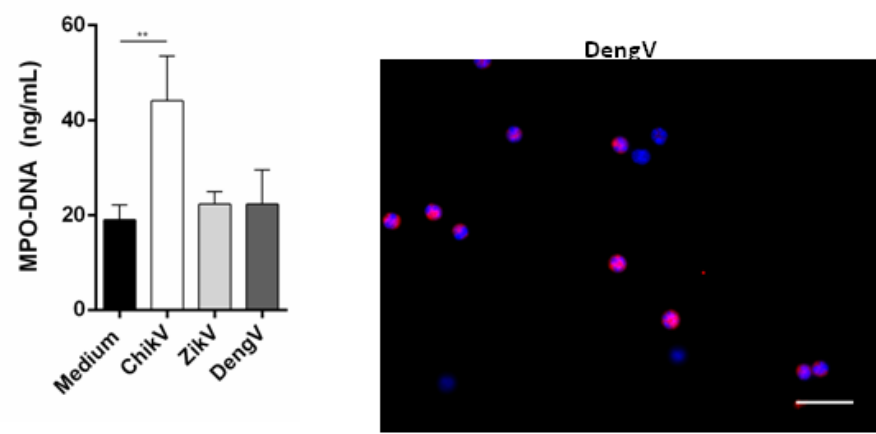

ChikV

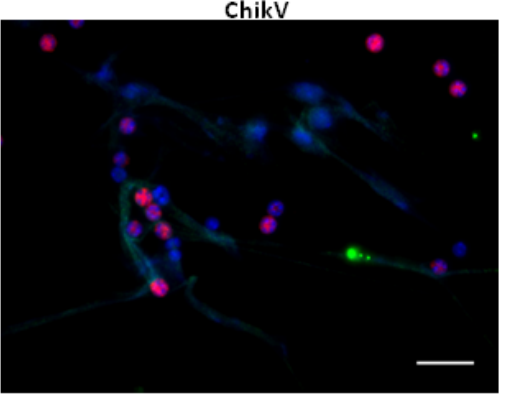

ZikV

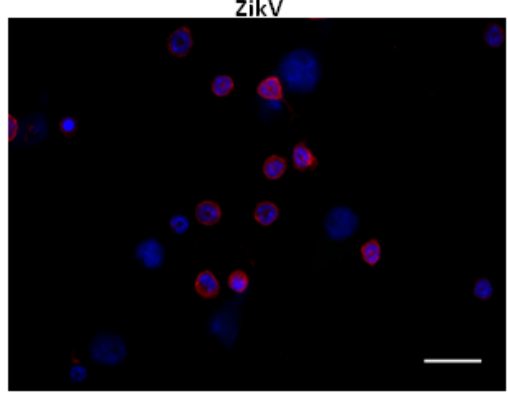

Figura 3. $O$ vírus Chikungunya, mas não Dengue e Zika, é capaz de induzir a produção de NETs em neutrófilos murinos. (A) A produção de NETs foi quantificada no sobrenadante de neutrófilos murinos incubados com Chikungunya, por 1, 2, 4 e 8 horas, em MOI de 0.5, 5 e 50 utilizando a metodologia MPO-DNA PicoGreen. (B) Produção de NETs quantificados no sobrenadante de neutrófilos murinos incubados com Chikungunya, Zika e Dengue, por 4 horas, em MOI de 5. (C) Imunofluorescência de neutrófilos murinos incubados com os vírus Zika, Dengue e Chikungunya, por 4 horas, em MOI 5. Foi feita a marcação de DNA utilizando DAPI (azul), marcação de neutrófilos utilizando anticorpo Anti-Ly6G (vermelho) e de NETs através da

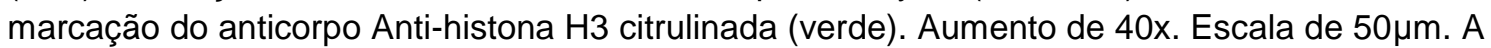
análise estatística foi feita utilizando análise de multivariância ANOVA seguido do teste de Bonferroni. O grupo foi considerado como estatisticamente diferente do grupo Meio quando 0 $p<0.05$. Dados representativos de dois experimentos independentes.

\subsection{A indução de NETose induzida por Chikungunya é dependente do}

\section{receptor Toll-Like 7}

Receptores Toll-Like são responsáveis por reconhecer e induzir uma resposta antiviral. Em particular, o receptor Toll-Like 7 (TLR7) é capaz de reconhecer vírus de RNA simples fita e induzir a NETose (Saitoh et al., 2012).

Uma vez que o vírus Chikungunya apresenta esta estrutura genética, fomos 
avaliar se na ausência do receptor Toll-Like 7, a geração de NETs ainda ocorria. Como o único animal ausente deste receptor também não possui os receptores Toll-Like 3 e Toll-Like 9 (TLR 3/7/9 $9^{-1 /}$ ), avaliamos a produção de NETs nos animais $\mathrm{TLR3}^{-/}$e $\mathrm{TLR9}^{-/}$também, isoladamente. Como resultado, encontramos que os neutrófilos isolados do animal TLR3/7/9-/ não produziam NETs, enquanto os neutrófilos dos animais selvagem, $\mathrm{TLR}^{-/}$e $\mathrm{TLR}^{-{ }^{-1}}$ eram capazes (Fig. 4A). Deste modo, demonstramos que o receptor que reconhece 0 vírus Chikungunya e inicia a NETose é o receptor Toll-Like 7.

Como este receptor encontra-se na região intracelular, fomos avaliar se este vírus era capaz de infectar neutrófilos para poder ser reconhecido. Encontramos que com trinta minutos de incubação, já era possível detectar marcação para o vírus dentro de neutrófilos murinos selvagens (Fig. 4B). Assim, demonstramos que o vírus Chikungunya é capaz de infectar neutrófilos murinos com trinta minutos e posteriormente ser reconhecido pelo receptor Toll-Like 7. 


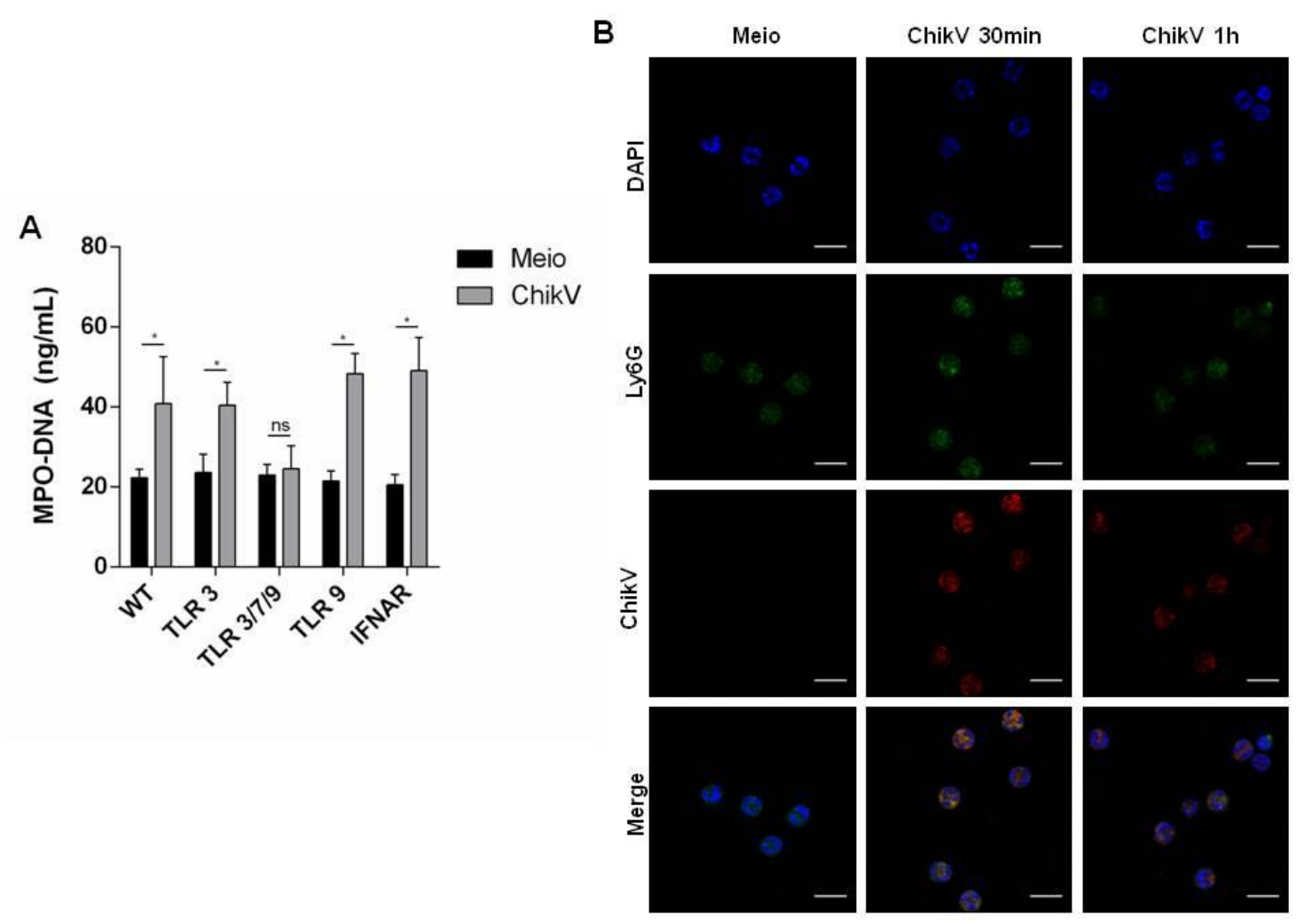

Figura 4. A liberação de NETs induzida por Chikungunya é dependente do receptor intracelular Toll-Like 7. (A) Neutrófilos de camundongos C57BL/6, TLR3 ${ }^{-1}$, TLR $3 / 7 / 9^{-1}$, TLR9 ${ }^{-1}$ e IFNAR ${ }^{-1}$ foram isolados e incubados com Chikungunya, em MOI de 5 , por quatro horas. $O$ sobrenadante foi coletado para dosagem de NETs por MPO-DNA PicoGreen. (B) Neutrófilos murinos foram incubados com Chikungunya, em $\mathrm{MOI}$ de 5 , por trinta minutos e uma hora. Foi feita a marcação de DNA utilizando DAPI (azul), de membrana de neutrófilos, utilizando anticorpor anti-Ly6G (verde) e de Chikungunya, utilizando anticorpo anti-Chikungunya (vermelho). Aumento de 63x. Escala de $20 \mu \mathrm{m}$. A análise estatística foi feita utilizando teste $T$ de Student. $\mathrm{O}$ grupo foi considerado como estatisticamente diferente do grupo Meio quando 0 $p<0.05$. Dados representativos de dois experimentos independentes.

\subsection{0 vírus Chikungunya induz uma NETose dependente de espécies}

\section{reativas de oxigênio}

Uma vez que apenas o vírus Chikungunya induziu a geração de NETs, fomos avaliar quais seriam os possíveis mecanismos responsáveis por essa produção. Como a NETose pode seguir por vias que dependem ou 
independem da produção de espécies reativas de oxigênio, fomos avaliar se o Chikungunya era capaz de induzi-las. Como era possível detectar NETs com quatro horas de incubação, buscamos avaliar se o vírus Chikungunya, no MOI de 5 , induzia a produção de espécies reativas oxigênio previamente a este tempo. Encontramos que esta produção aumentava com uma hora e mantinham-se constante até duas horas de incubação com o vírus (Fig. 5A).

Para poder relacionar essa produção de espécies reativas de oxigênio com a liberação de NETs, utilizamos Apocinina, um inibidor farmacológico da enzima NADPH oxidase. Pré-tratamos as células com Apocinina na concentração de 300uM, por trinta minutos, condição em que já é descrita por inibir a produção de espécies reativas de oxigênio (Trevelin et al., 2016) e avaliamos a produção de NETs. Observamos que a inibição farmacológico da produção de espécies reativas de oxigênio prejudicou a geração de NETs induzida por Chikungunya (Fig. 5B), sugerindo que a NETose induzida por este vírus é dependente de espécies reativas de oxigênio. 


\section{B}
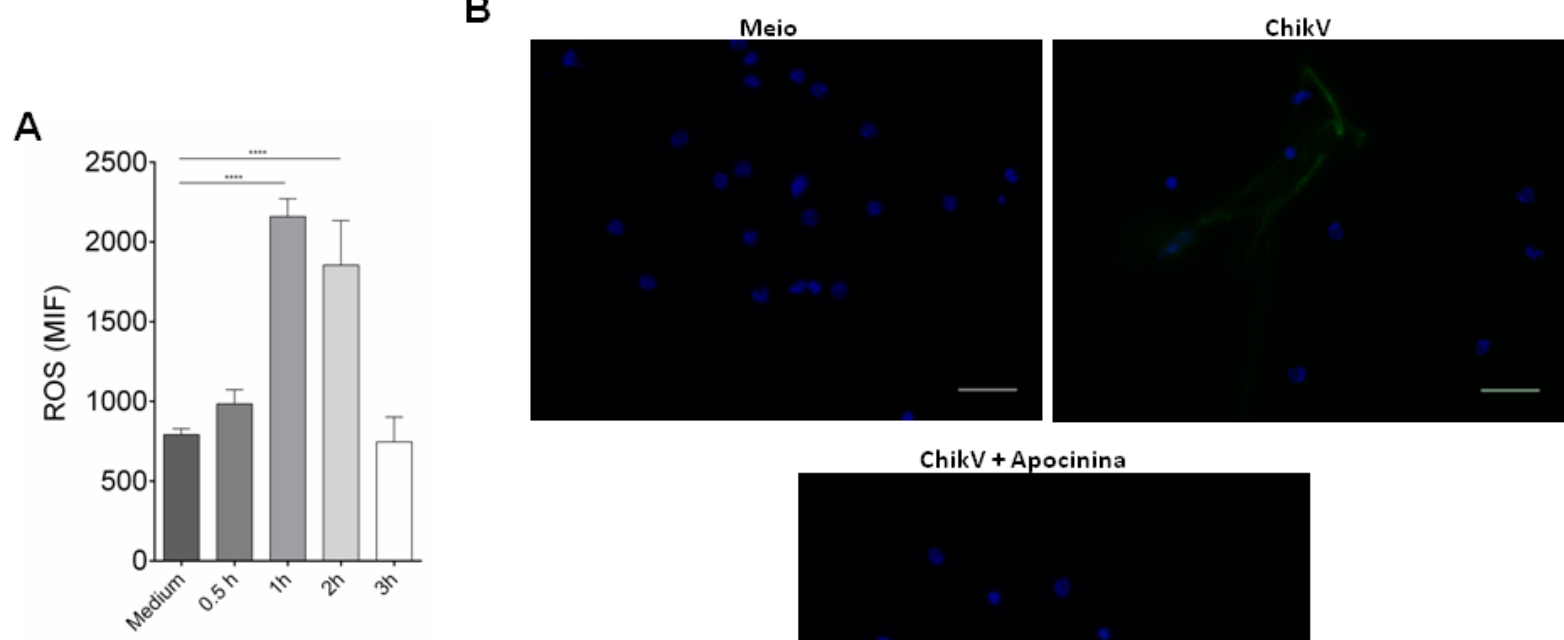

ChikV + Apocinina

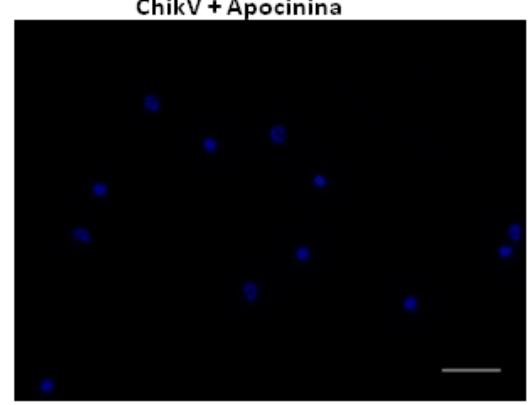

Figura 5. A liberação de NETs induzida por Chikungunya é dependente de produção de espécies reativas de oxigênio. (A) A produção de espécies reativas de oxigênio foi quantificada utilizando a sonda CM-H2DCFDA em neutrófilos murinos incubados com Chikungunya, em MOI de 5, por trinta minutos, uma hora, duas horas ou três horas e avaliado por citometria de fluxo. (B) Imunofluorescência de neutrófilos murinos pré-tratados com Apocinina (uM) por trinta minutos e depois incubados com Chikungunya, em $\mathrm{MOI}$ de 5, por quatro horas. Foi feita marcação de DNA utilizando DAPI (azul) e NETs utilizando anticorpo

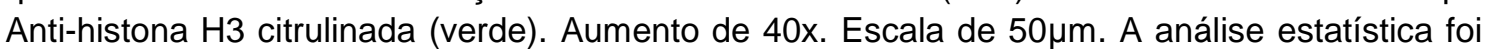
feita utilizando análise de multivariância ANOVA seguido do teste de Bonferroni. O grupo foi considerado como estatisticamente diferente do grupo Meio quando $0 p<0.05$. Dados representativos de dois experimentos independentes.

\subsection{0 vírus Chikungunya é capturado e neutralizado pelas NETs}

Uma vez demonstrado que o vírus Chikungunya é capaz de induzir a geração de NETs, fomos avaliar se estas possuem uma relevância imunológica, sendo capazes de combater a sua infecção. Para isso, NETs de neutrófilos murinos induzidos por PMA (100ng/mL) foram digeridos ou não com rhDNAse (Roche) e quantificados (Fig. 6A). Em seguida, incubamos os sobrenadantes com o vírus Chikungunya por uma hora e avaliamos a 
capacidade de infecção do vírus por ensaio de formação de placa (Fig. 6B). Demonstramos que quando incubado com sobrenadante contendo altos níveis de NETs, o vírus Chikungunya não é capaz de infectar as células. Porém, quando incubados com sobrenadante em que as NETs foram degradadas, 0 vírus apresenta uma maior capacidade infecciosa, em relação ao anterior, sugerindo que as NETs possuem um papel em sua neutralização (Fig. 6B).

Para comprovar se as NETs realmente eram capazes de capturar 0 vírus, incubamos neutrófilos murinos com o vírus Chikungunya e realizamos uma imunofluorescência marcando NETs e o vírus. Observamos que havia colocalização das três marcações (DAPI, histona H3 citrulinada e Chikungunya), sugerindo que as NETs estavam capturando o Chikungunya, e que este evento não ocorria mais uma vez que essas marcações não mais se encontravam quando as NETs eram degradadas com rhDNAse (Fig. 6C). Deste modo, demonstramos que as NETs são capazes de capturar o vírus Chikungunya e impedir sua infecção. 

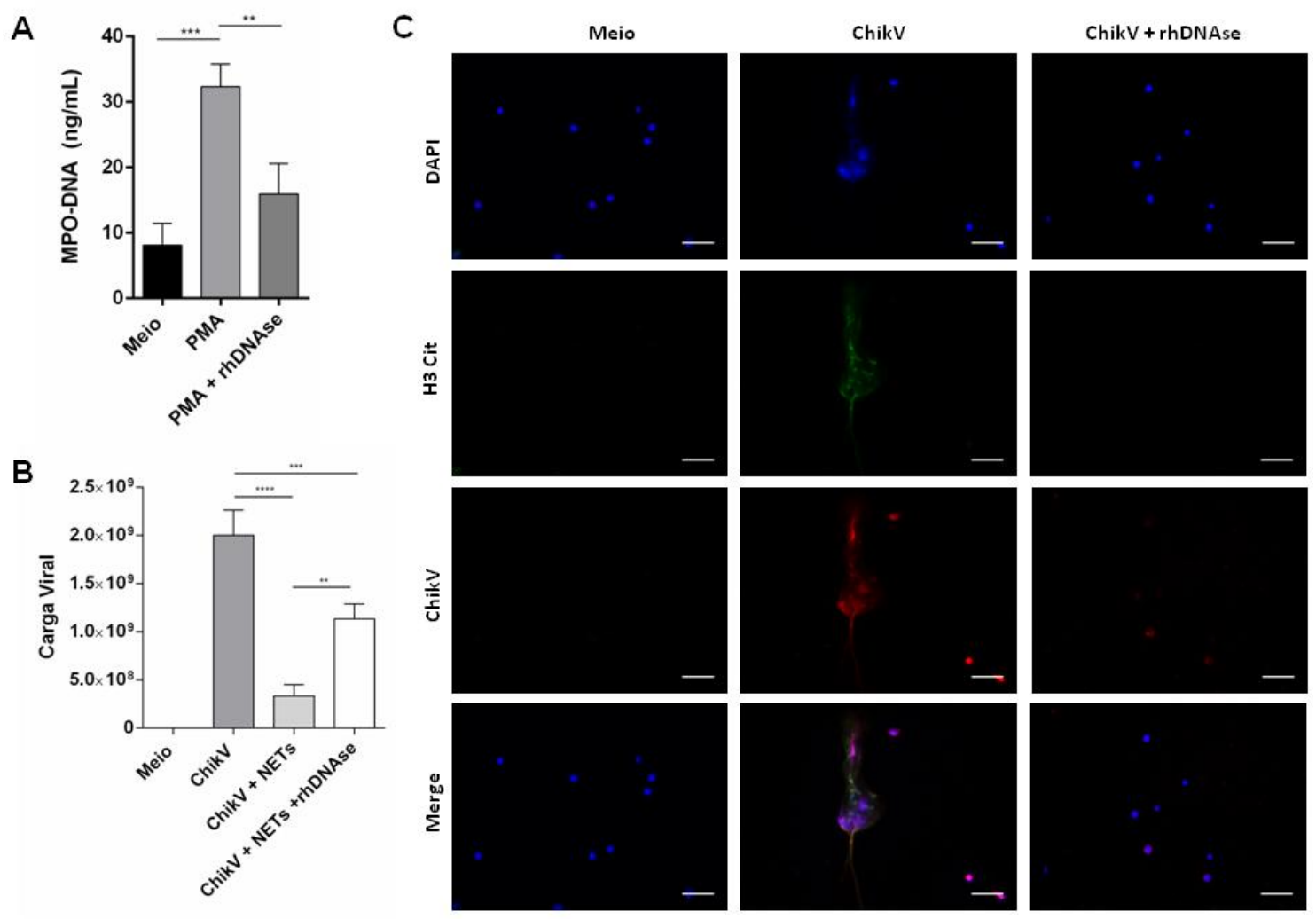

Figura 6. NETs são capazes de capturar e neutralizar o vírus Chikungunya. (A) Neutrófilos murinos foram incubados ou não com PMA (100ng/mL) ou meio, por quatro horas. Os sobrenadantes foram coletados, acrescidos ou não de rhDNAse (digestão das NETs) e quantificados por MPO-DNA PicoGreen. (B) Os sobrenadantes obtidos foram incubados com Chikungunya por uma hora e foi feito um ensaio de formação de placa. (C) Imunofluorescência de neutrófilos murinos incubados com Chikungunya, em $\mathrm{MOI}$ de 5 , por quatro horas. Foi feita marcação de DNA utilizando DAPI (azul), NETs utilizando anticorpo Anti-histona H3 citrulinada (verde) e de Chikungunya utilizando anticorpo Anti-Chikungunya (vermelho). Aumento de 40x. Escala de $50 \mu \mathrm{m}$. A análise estatística foi feita utilizando análise de multivariância ANOVA seguido do teste de Bonferroni. O grupo foi considerado como estatisticamente diferente do grupo Meio quando o $p<0.05$. Dados representativos de três experimentos independentes.

\subsection{Camundongos infectados com Chikungunya tratados com rhDNAse}

para degradar as NETs sistêmicas apresentam maior carga viral no sangue e são mais suscetíveis à infecção

Uma vez demonstrada a capacidade do vírus Chikungunya induzir NETose por uma via dependente de espécies reativas de oxigênio e TLR7, e esta ser capaz de capturar e neutralizar o vírus in vitro, fomos avaliar sua 
relevância in vivo em modelos de infecção viral. Utilizamos animais $\mathrm{IFNAR}^{-/}$, os quais são descritos por serem mais suscetíveis à infecção viral. É importante mencionar que os animais selvagens não demonstram sinais de infecção. Para retirar algum possível viés da sinalização de Interferon na produção de NETs, demonstramos que neutrófilos isolados desses animais são capazes de produzir NETs, de forma similar aos animais selvagens (Fig. 4A).

Padronizamos a dose de infecção de $3.10^{1}$ PFU, administrada via intraperitoneal, no qual trinta por cento dos animais sobrevivem após o quinto dia (Fig 7A). Tratamos os animais com $10 \mathrm{mg} / \mathrm{kg}$ com rhDNAse, a cada $12 \mathrm{~h}$, administrada via subcutânea, até o quinto dia de infecção. Observamos que os animais infectados e tratados com rhDNAse apresentavam $100 \%$ de mortalidade até o quinto dia, enquanto em torno de trinta por cento dos animais apenas infectados sobreviviam (Fig. 7A).

Adicionalmente, realizamos uma coleta de sangue a cada $24 \mathrm{~h}$ dos grupos mencionados para avaliar níveis sistêmicos de NETs e de carga viral. Observamos que os animais infectados e sem tratamento apresentavam um aumento crescente significante nos níveis de NETs entre o segundo dia e o terceiro dias de infecção, o qual retornava ao basal no quarto dia. Em relação a sua carga viral, estes animais apresentavam um aumento da carga viral no segundo dia, porém esta reduzia no terceiro dia e posteriormente era indetectável no quarto dia (Fig.7B).

Por outro lado, os animais tratados com rhDNAse não apresentaram um aumento nos níveis sistêmicos de NETs, com apenas um pequeno aumento significativo no quarto dia. Porém, estes animais já apresentavam alta carga 
viral no primeiro dia de infecção, que se mantinha elevada no segundo e sofria uma diminuição parcial no terceiro e quarto dias (Fig. 7B). Deste modo, podemos observar que quando degradamos as NETs em modelos suscetíveis à infecção por Chikungunya, estes não são capazes de controlar a infecção inicial, aumentando a carga viral em seu sangue e, consequentemente, levando todos os animais a óbito.
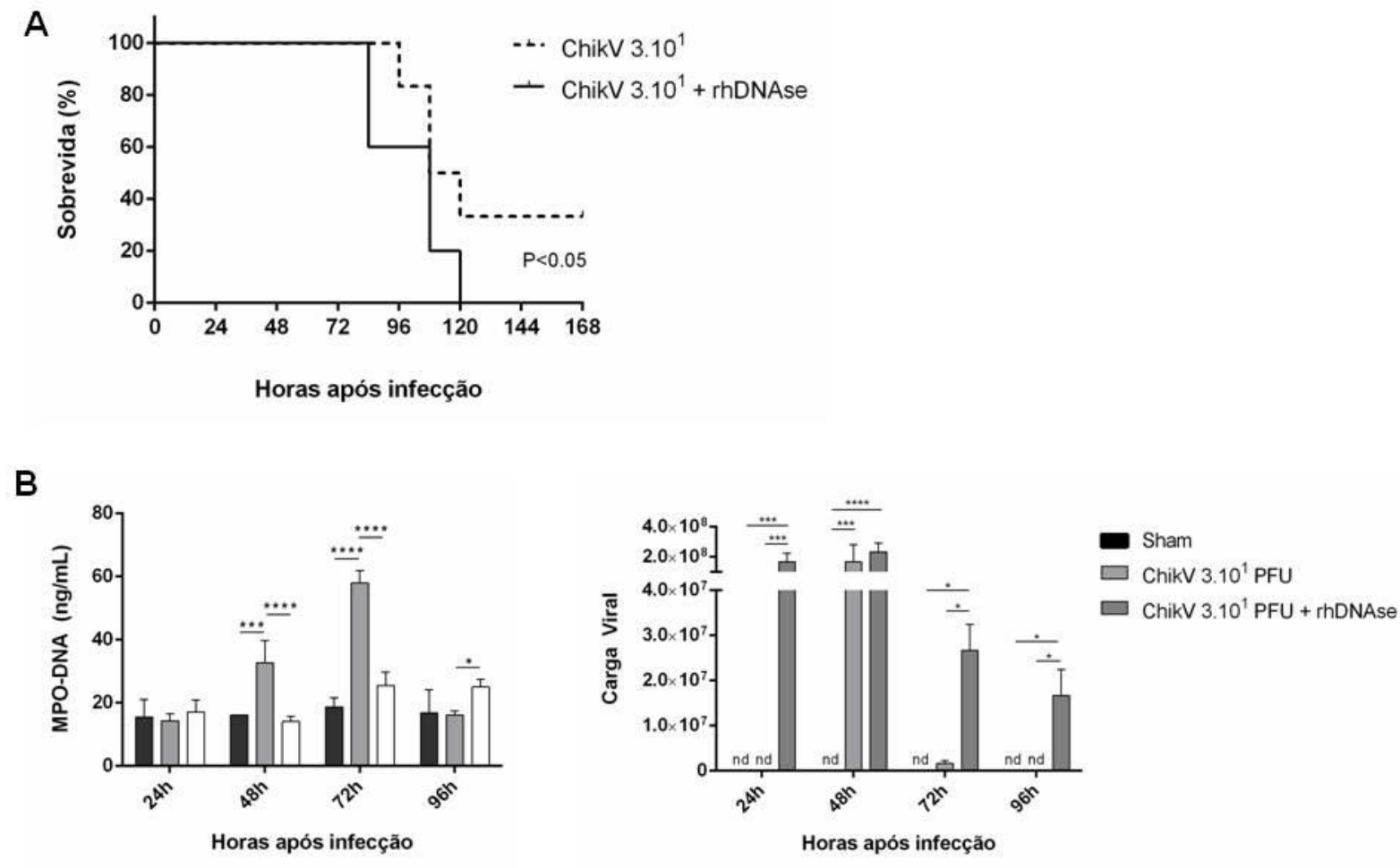

Figura 7. Animais IFNAR ${ }^{-/}$infectados com Chikungunya apresentam maior carga viral e menos NETs no sangue quando tratados com rhDNAse e morrem mais. (A) Animais IFNAR $^{-1-}$ foram infectados com 3.10 ${ }^{1}$ PFU de Chikungunya, via intraperitoneal. Um grupo foi tratado com rhDNAse $(10 \mathrm{mg} / \mathrm{kg})$ e outro com salina, a cada $12 \mathrm{~h}$ após a infecção e foi feita a avaliação de sobrevida a cada $12 \mathrm{~h}$. (B) Sangue foi coletado a cada $24 \mathrm{~h}$ após a infecção e foi feita avaliação de NETs por MPO-DNA PicoGreen e de carga viral por ensaio de formação de placa. A análise estatística foi feita utilizando análise de multivariância TWO WAY ANOVA seguido do teste de Bonferroni. O grupo foi considerado como estatisticamente diferente do grupo Sham quando o $p<0.05$. Dados representativos de três experimentos independentes.

\subsection{NETs são liberadas em neutrófilos humanos incubados com Chikungunya, mas não com Zika e Dengue}


Uma vez demonstrado o papel das NETs no modelo murino, fomos avaliar se o fenótipo era reprodutível em células humanas. Assim, similarmente ao observado em camundongo, encontramos que apenas o Chikungunya foi capaz de induzir a liberação de NETs em neutrófilos humanos (Fig. 8A e Fig. 8B).

A

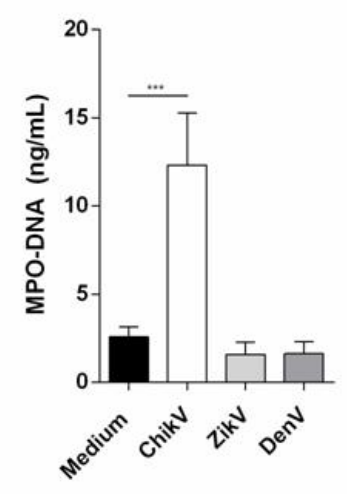

B

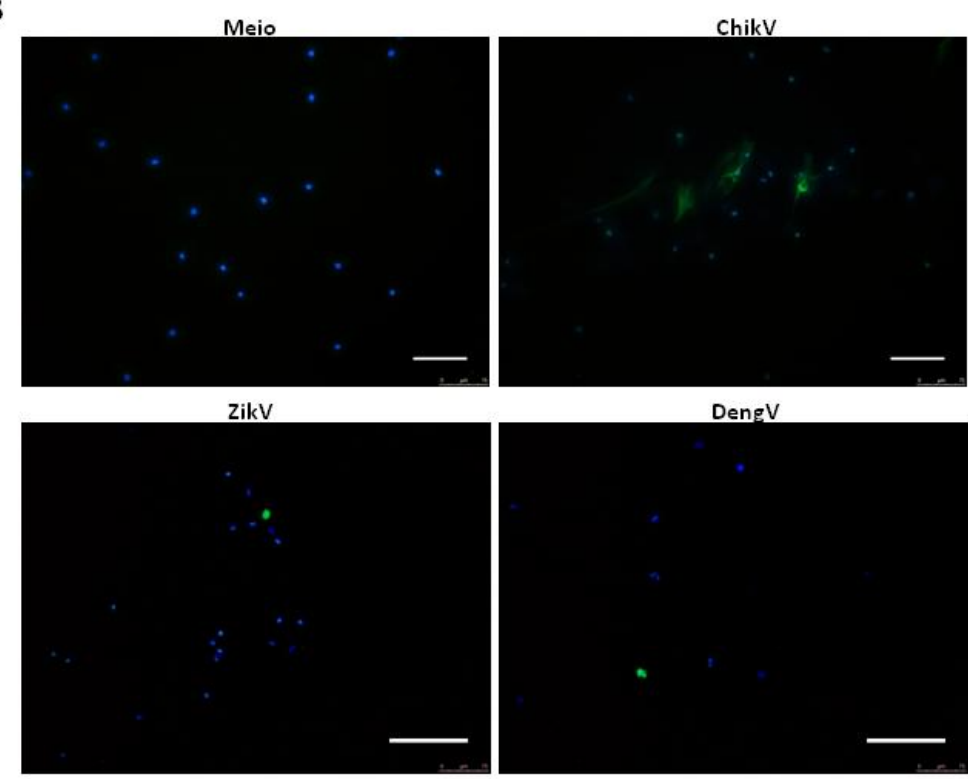

Figura 8. O vírus Chikungunya, mas não Dengue e Zika, é capaz de induzir a liberação de NETs em neutrófilos. (A) A produção de NETs foi quantificada utilizando a metodologia MPODNA PicoGreen a partir do sobrenadante de neutrófilos humanos incubados com os vírus Zika, Dengue e Chikungunya, por 4 horas, em MOI 5. (B) Imunofluorescência de neutrófilos humanos incubados com os vírus Zika, Dengue e Chikungunya, por 4 horas, em MOI 5. Foi feita a marcação de DNA utilizando DAPI (azul) e de NETs através da marcação do anticorpo Anti-histona H3 citulinada (verde). Aumento de 20x. Escala de $75 \mu \mathrm{m}$. Para dosagem de NETs em neutrófilos humanos, a análise estatística foi feita utilizando análise de multivariância ANOVA seguido do teste de Bonferroni. $O$ grupo foi considerado como estatisticamente diferente do grupo Meio quando $\circ p<0.05$. Dados representativos de dois experimentos realizados independentes.

\subsection{Pacientes infectados com Chikungunya apresentam maiores níveis de}

\section{NETs relacionados com um aumento na carga viral}


Para explorar um contexto mais clínico, dosamos NETs no soro de pacientes infectados com Chikungunya diagnosticados na fase aguda. Quando comparado com amostras de soro de controles saudáveis, encontramos um aumento nos níveis de NETs nas amostras de pacientes (Fig. 9A). Mais além, obtivemos os valores de CT (do inglês cycle threshold) das reações de RTPCR de diagnóstico das amostras, onde quanto menor o valor do CT, maior é a carga viral do paciente. Encontramos uma relação significativa no qual as amostras que apresentavam maiores níveis de NETs também apresentavam maiores níveis de carga viral (9B). Assim, demonstramos que as NETs são produzidas na infecção aguda por Chikungunya em resposta à uma alta carga viral.

A

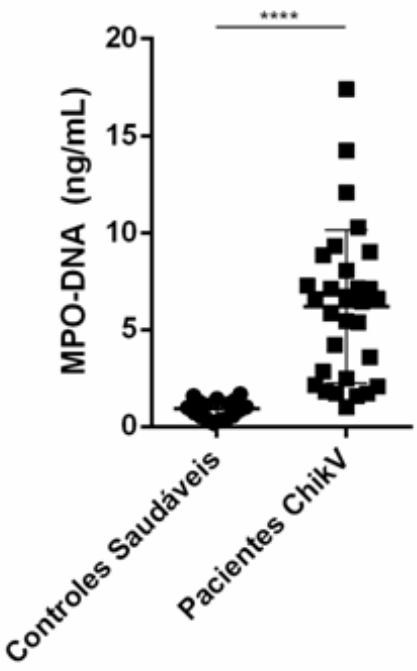

B

$R^{2}=0.3904(p=0.0011 ; n=20)$

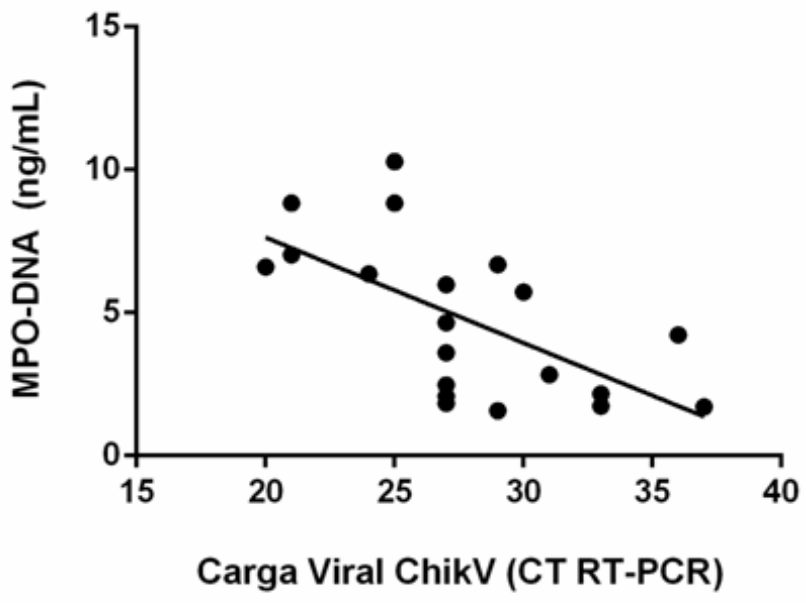

Figura 9. NETs estão aumentadas no soro de pacientes infectados com Chikungunya e estão correlacionadas com maior carga viral. . (A) Soro de pacientes infectados com Chikungunya em fase aguda foi utilizado para dosagem de NETs por MPO-DNA PicoGreen (B) e foi feita uma correlação entre os níveis de NETs e a carga viral, avaliada por RT-PCR. Para dosagem de NETs no soro de pacientes, foi feito o teste Mann-Whitney. O grupo foi considerado como estatisticamente diferente do grupo Controles Saudáveis quando o $p<0.05$. Para correlação dos valores de NETs e carga viral, foi utilizado o teste de correlação de Spearman. 
DISCUSSÃO 


\section{DISCUSSÃO}

Infecções emergentes por arbovírus vêm aumentando sua frequência consideravelmente nos últimos anos, afetando milhões de pessoas anualmente e causando sérios problemas de saúde pública (Amdekar et al., 2017). Este aumento ocorre devido a diversos fatores, como globalização, adaptação dos vetores a ambientes urbanos e mutações no genoma viral. Mais além, essas infecções estão sendo cada vez mais associadas ao surgimento de sintomas graves, como artrite reumatoide e complicações neurológicas, comprometendo o bem-estar físico dos pacientes (Weaver et al., 2018). Deste modo, compreender os mecanismos patológicos dessas infecções é importante para descoberta de possíveis intervenções terapêuticas, que auxiliariam no tratamento destes pacientes.

Em nosso estudo, demonstramos pela primeira vez que o vírus Chikungunya é capaz de induzir a liberação de NETs em neutrófilos murinos e humanos, sendo um mecanismo dependente de produção de espécies reativas de oxigênio e internalização do vírus via reconhecimento pelo receptor Toll-Like 7. Mais além, sugerimos que as NETs são capazes de capturar e neutralizar o vírus in vitro e camundongos infectados tornam-se mais suscetíveis quando tratados com rhDNAse. Por fim, demonstramos que pacientes em fase aguda de infecção por Chikungunya possuem maiores níveis plasmáticos de NETs, o que foi correlacionado com uma maior carga viral.

Neutrófilos são as primeiras células de defesa a chegarem ao foco infeccioso para controle do patógeno, porém poucos trabalhos demonstram o 
papel desta célula em infecções virais (Gabriel et al., 2013). Foi demonstrado que neutrófilos humanos incubados com vírus da Dengue do tipo 2 aumentam a expressão de moléculas antivirais como $\alpha$-defensinas e LL-37, possivelmente contribuindo para combater o patógeno (Castañeda-Sánchez et al., 2016). Em infecções por Zika, Manangeeswaran et al demonstraram que animais IFNAR ${ }^{-/-}$ infectados com este vírus, apresentam um infiltrado de macrófagos e neutrófilos em seu sistema nervoso central, juntamente com um aumento na expressão de IL-6, TNF- $\alpha$ e IL-1 (Manangeeswaran et al., 2016).

Em infecções por Chikungunya, foi demonstrado que em modelo animal de peixe zebra infectado por este vírus os neutrófilos são a principal célula produtora de Interferon do tipo I, controlando a infecção (Palha et al., 2013). Adicionalmente, modelos murinos de C57BL/6 infectados com Chikungunya na pata apresentam uma infecção aguda que perdura por alguns dias (Haese et al., 2016). Neste modelo, o principal infiltrado celular consiste de monócitos, porém, quando animais $\mathrm{CCR}^{-/}$são infectados, ocorre uma troca por um infiltrado de neutrófilos, gerando um aumento em citocinas pró-inflamatórias e maior inchaço da pata, sugerindo que neste modelo, os neutrófilos podem estar contribuindo para sua imunopatologia. Porém, não houve demonstração se esses neutrófilos estavam produzindo NETs (Poo et al., 2014).

Mesmo após quase quinze anos desde que as NETs foram descritas (Brinkmann et al., 2004), pouco se sabe acerca de seus mecanismos e sua relevância no contexto imunológico e patológico. Em infecções por vírus, as NETs possuem um papel controverso, sendo associadas tanto à proteção quanto a sua imunopatologia (Schönrich et al., 2016). 
Até o momento, o único trabalho que demonstrou o papel desse mecanismo em infecções arbovirais foi Moreno-Altamirano et al. Os autores demonstraram que Dengue do tipo 2 foi capaz de inibir a produção de NETs em neutrófilos humanos pré-incubados com o vírus e estimulados com PMA. Este efeito ocorreu, pois a Dengue foi capaz de inibir a internalização de glicose na célula (Moreno-Altamirano et al., 2015). Este protocolo não foi reprodutível em nosso laboratório com os vírus Dengue e Zika, os quais não foram capazes de inibir a NETose, possivelmente devido à diferença metodológica abordada (dados não mostrados). No trabalho de MorenoAltamirano, as NETs foram marcadas apenas com DAPI, o qual é um marcador de DNA, não sendo específico para NETs. Em nossa metodologia, utilizamos, além de DAPI, a marcação de histona $\mathrm{H} 3$ citrulinada, a qual é formada durante o processo de NETose pela ativação de PAD4, que deamina arginina nas histonas, convertendo para citrulina, o que resulta na descondensação do DNA para formação das NETs (Li et al., 2010).

Assim, nosso estudo é pioneiro em demonstrar que neutrófilos são capazes de liberar NETs em resposta a infecção por Chikungunya, através de sua internalização, reconhecimento pelo receptor Toll-Like 7 e produção de espécies reativas de oxigênio. Em 1979, Levitt et al sugeriram que neutrófilos murinos não eram permissíveis à infecção por Alphavírus. Neste trabalho, neutrófilos foram incubados com o vírus e foi feita a avaliação de carga viral no sobrenadante a cada $24 \mathrm{~h}$ por ensaio de formação de placa. Como a carga viral era reduzida até ser indetectável com 48h, Levitt interpretou que neutrófilos não eram infectados por Alphavírus (Levitt et al., 1979). Porém, fazendo uma análise com contextos mais atuais, pode-se interpretar que a incubação pode 
ter ativado os neutrófilos a produzirem NETs, que possivelmente inativaram o vírus, o que foi observado em nossos dados.

Saitoh et al demonstrou que o vírus HIV induz NETose em neutrófilos humanos através dos receptores Toll-Like 7 e 8 , por meio de um mecanismo dependente de produção de espécies reativas de oxigênio, resultando em captura e eliminação viral (Saitoh et al., 2012). Mais além, Barr et al demonstraram que neutrófilos obtidos do trato genital feminino são capazes de liberar NETs por mecanismos parecidos e que também resultam na inativação do vírus HIV e proteção do hospedeiro (Barr et al., 2018). Apesar de possuírem classificações distintas, ambos os vírus HIV e Chikungunya possuem a estrutura genética de serem fitas simples de RNA. Em nossos dados, demonstramos que os mecanismos de indução de NETose pelo Chikungunya são similares aos encontrados por Saitoh et al e Barr et al, dependendo do receptor Toll-Like 7 e produção de espécies reativas de oxigênio, inativando o patógeno. Esta similaridade pode ser devida à semelhança estrutural de ambos serem RNAs de fita simples, portanto, sendo reconhecido pelo mesmo receptor de reconhecimento padrão, desencadeando mecanismos intracelulares semelhantes, que resultam em liberação de NETs.

Porém, nos estudos citados de NETs e HIV não há a demonstração da importância fisiológica deste mecanismo. Em nossos estudos, utilizando de modelos de infecção viral, comprovamos que ao diminuir os níveis circulantes de NETs com o uso de rhDNAse, o animal torna-se mais suscetível à infecção. Resultados semelhantes foram observados por Jenne et al, em modelos de infecção por Myxoma vírus. Os autores demonstraram que após a infecção, as NETs eram induzidas in vivo, por um mecanismo dependente de ativação de 
plaquetas, e protegiam os hepatócitos da infecção viral. Contudo, ao tratar o animal com DNAse, observava-se uma perda parcial desta proteção (Jenne et al., 2013). Mesmo sendo uma NETose desencadeada por um mecanismo distinto ao de nosso estudo, este trabalho ressalta a importância das NETs no contexto de proteção do hospedeiro frente a uma infecção viral.

Por outro lado, Narasaraju et al demonstrou em modelos animais que durante a infecção por Influenza pneumonia, NETs são formadas nos capilares alveolares, porém acabam levando ao dano endotelial, comprometendo a função fisiológica do órgão (Narasaraju et al., 2011). Mais além, animais modelos para asma infectados com rinovírus tiveram uma liberação de NETs nos pulmões e apresentaram uma piora do quadro clínico, sendo revertido com o tratamento de DNAse (Toussaint et al., 2017). Assim, as NETs podem apresentar uma função ambígua na infecção viral, podendo auxiliar na eliminação do patógeno ou contribuir para a imunopatologia desta. Contudo, foi sugerido que este efeito colateral pode não ser tão maléfico, uma vez que se as NETs forem liberadas perto da área infectada, além de capturarem diretamente o vírus, estas podem contribuir no combate a infecção tendo um efeito citotóxico nas células infectadas, eliminando o reservatório viral (Jenne et al., 2015).

Em um contexto clínico, já foi demonstrado o papel das NETs em pacientes infectados por vírus. Raftery et al demonstraram que pacientes infectados por Hantavírus apresentavam maiores níveis de NETs sistêmicos e nos rins, que foram diminuindo conforme a resolução da doença. Mais além, os altos níveis de NETs foram relacionados a uma geração de autoanticorpos contra DNA, o que poderia contribuir para o desenvolvimento de Lupus 
Eritematoso Sistêmico (Raftery et al., 2014). Concomitantemente, Zhu et al correlacionou dados de pacientes infectados por Influenza A e demonstrou que quanto maiores os níveis de NETs, maior era o agravamento da infecção (Zhu et al., 2018). Em nossos dados, demonstramos que os níveis plasmáticos de NETs encontram-se aumentados em pacientes infectados com Chikungunya e estes níveis foram correlacionados com uma maior carga viral. Sugerimos que este aumento das NETs ocorre como uma resposta ao vírus, de forma carga dependente, porém ainda não pudemos correlacionar com dados clínicos dos pacientes para direcionar se estas NETs possuem um efeito protetor ou maléfico em pacientes.

As infecções por Arbovírus apresentam uma alta frequência, principalmente em países de clima tropical, acometendo milhões de pessoas (Weaver et al., 2018). Como mencionado, as NETs podem possuir papel ambíguo em infecções, levando ao controle do patógeno ou dano tecidual. Em conjunto, nossos dados demonstram que neutrófilos são capazes de responder à infecção por Chikungunya, mas não de Zika ou Dengue, liberando NETs por meio de internalização do patógeno, reconhecimento por Toll-Like 7 e produção de espécies reativas de oxigênio. Essas NETs são capazes de capturar e neutralizar o vírus, protegendo o hospedeiro, em modelo murino. Mais além, demonstramos que pacientes em fase aguda de Chikungunya possuem altos níveis plasmáticos de NETs, o que foi relacionado à maior carga viral. Deste modo, mais estudos devem ser realizados a fim de explorar o papel das NETs nessas infecções para o desenvolvimento de possíveis tratamentos futuros. 
CONCLUSÃO 


\section{CONCLUSÃO}

Nosso estudo demonstrou que neutrófilos humanos e murinos incubados especificamente com Chikungunya são capazes de liberar NETs. Mecanisticamente, este fenômeno ocorre por meio dependente de sua internalização, reconhecimento pelo receptor Toll-Like 7 e produção de espécies reativas de oxigênio. Mais além, demonstramos que as NETs são capazes de capturar e neutralizar o vírus, diminuindo consideravelmente sua infecção. Adicionalmente, demonstramos que as NETs ajudam no combate ao vírus in vivo e que pacientes infectados possuem aumento nos níveis plasmáticos de NETs. 


\section{REFERÊNCIAS}

\subsection{REFERÊNCIAS}

Agraz-Cibrian, J.M., Giraldo, D.M., Mary, F.M. and Urcuqui-Inchima, S., 2017. Understanding the molecular mechanisms of NETs and their role in antiviral innate immunity. Virus research, 228, pp.124-133.

Amdekar, S., Parashar, D. and Alagarasu, K., 2017. Chikungunya VirusInduced Arthritis: Role of Host and Viral Factors in the Pathogenesis. Viral immunology, 30(10), pp.691-702.

An, W., Ge, N., Cao, Y., Sun, J. and Jin, X., 2017. Recent progress on chikungunya virus research. Virologica Sinica, pp.1-13.

Aratani, Y., 2018. Myeloperoxidase: its role for host defense, inflammation, and neutrophil function. Archives of biochemistry and biophysics.

azzaq Belaaouaj, A., Kim, K.S. and Shapiro, S.D., 2000. Degradation of outer membrane protein A in Escherichia coli killing by neutrophil elastase. Science, 289(5482), pp.1185-1187.

Barr, F.D., Ochsenbauer, C., Wira, C.R. and Rodriguez-Garcia, M., 2018. Neutrophil extracellular traps prevent HIV infection in the female genital tract. Mucosal immunology, p.1.

Beiter, K., Wartha, F., Albiger, B., Normark, S., Zychlinsky, A. and HenriquesNormark, B., 2006. An endonuclease allows Streptococcus pneumoniae to escape from neutrophil extracellular traps. Current Biology, 16(4), pp.401-407. 
Berends, E.T., Horswill, A.R., Haste, N.M., Monestier, M., Nizet, V. and von Köckritz-Blickwede, M., 2010. Nuclease expression by Staphylococcus aureus facilitates escape from neutrophil extracellular traps. Journal of innate immunity, 2(6), pp.576-586.

Bernard, E., Solignat, M., Gay, B., Chazal, N., Higgs, S., Devaux, C. and Briant, L., 2010. Endocytosis of chikungunya virus into mammalian cells: role of clathrin and early endosomal compartments. PLoS One, 5(7), p.e11479.

Bonaventura, A., Liberale, L., Carbone, F., Vecchié, A., Diaz-Cañestro, C., Camici, G.G., Montecucco, F. and Dallegri, F., 2018. The pathophysiological role of neutrophil extracellular traps in inflammatory diseases. Thrombosis and haemostasis, 118(01), pp.006-027.

Brinkmann, V. and Zychlinsky, A., 2007. Beneficial suicide: why neutrophils die to make NETs. Nature Reviews Microbiology, 5(8), p.577.

Brinkmann, V., Reichard, U., Goosmann, C., Fauler, B., Uhlemann, Y., Weiss, D.S., Weinrauch, Y. and Zychlinsky, A., 2004. Neutrophil extracellular traps kill bacteria. science, 303(5663), pp.1532-1535.

Burt, Felicity J., et al. "Chikungunya virus: an update on the biology and pathogenesis of this emerging pathogen." The Lancet Infectious Diseases (2017).

Byrd, A.S., O’Brien, X.M., Johnson, C.M., Lavigne, L.M. and Reichner, J.S., 2013. An extracellular matrix-based mechanism of rapid neutrophil extracellular trap formation in response to Candida albicans. The Journal of Immunology, p.1202671. 
Carlin, A.F., Uchiyama, S., Chang, Y.C., Lewis, A.L., Nizet, V. and Varki, A., 2009. Molecular mimicry of host sialylated glycans allows a bacterial pathogen to engage neutrophil Siglec-9 and dampen the innate immune response. Blood, 113(14), pp.3333-3336.

Carvalho, L.O., Aquino, E.N., Neves, A.C.D. and Fontes, W., 2015. The neutrophil nucleus and its role in neutrophilic function. Journal of cellular biochemistry, 116(9), pp.1831-1836.

Chow, A., Her, Z., Ong, E.K., Chen, J.M., Dimatatac, F., Kwek, D.J., Barkham, T., Yang, H., Rénia, L., Leo, Y.S. and Ng, L.F., 2011. Persistent arthralgia induced by Chikungunya virus infection is associated with interleukin-6 and granulocyte macrophage colony-stimulating factor. Journal of Infectious Diseases, 203(2), pp.149-157.

Chow, A., Her, Z., Ong, E.K., Chen, J.M., Dimatatac, F., Kwek, D.J., Barkham, T., Yang, H., Rénia, L., Leo, Y.S. and Ng, L.F., 2011. Persistent arthralgia induced by Chikungunya virus infection is associated with interleukin- 6 and granulocyte macrophage colony-stimulating factor. Journal of Infectious Diseases, 203(2), pp.149-157.

Cortjens, B., De Boer, O.J., De Jong, R., Antonis, A.F., Sabogal Piñeros, Y.S., Lutter, R., Van Woensel, J.B. and Bem, R.A., 2016. Neutrophil extracellular traps cause airway obstruction during respiratory syncytial virus disease. The Journal of pathology, 238(3), pp.401-411.

Couderc, T., Chrétien, F., Schilte, C., Disson, O., Brigitte, M., GuivelBenhassine, F., Touret, Y., Barau, G., Cayet, N., Schuffenecker, I. and Desprès, P., 2008. A mouse model for Chikungunya: young age and inefficient 
type-I interferon signaling are risk factors for severe disease. PLoS pathogens, 4(2), p.e29.

Czaikoski, P.G., Mota, J.M.S.C., Nascimento, D.C., Sônego, F., Melo, P.H., Scortegagna, G.T., Silva, R.L., Barroso-Sousa, R., Souto, F.O., Pazin-Filho, A. and Figueiredo, F., 2016. Neutrophil extracellular traps induce organ damage during experimental and clinical sepsis. PloS one, 11(2), p.e0148142.

Dhanwani, R., Khan, M., Lomash, V., Rao, P.V.L., Ly, H. and Parida, M., 2014. Characterization of Chikungunya virus induced host response in a mouse model of viral myositis. PloS one, 9(3), p.e92813.

Dupuis-Maguiraga, L., Noret, M., Brun, S., Le Grand, R., Gras, G. and Roques, P., 2012. Chikungunya disease: infection-associated markers from the acute to the chronic phase of arbovirus-induced arthralgia. PLoS neglected tropical diseases, 6(3), p.e1446.

Egan, C.E., Sukhumavasi, W., Bierly, A.L. and Denkers, E.Y., 2008. Understanding the multiple functions of Gr-1+ cell subpopulations during microbial infection. Immunologic research, 40(1), pp.35-48.

Fattori, V., Amaral, F.A. and Verri, W.A., 2016. Neutrophils and arthritis: Role in disease and pharmacological perspectives. Pharmacological research.

Findlay, E.G., Currie, S.M. and Davidson, D.J., 2013. Cationic host defence peptides: potential as antiviral therapeutics. BioDrugs, 27(5), pp.479-493.

Funchal, G.A., Jaeger, N., Czepielewski, R.S., Machado, M.S., Muraro, S.P., Stein, R.T., Bonorino, C.B. and Porto, B.N., 2015. Respiratory syncytial virus 
fusion protein promotes TLR-4-dependent neutrophil extracellular trap formation by human neutrophils. PloS one, 10(4), p.e0124082.

Gabriel, C., Her, Z. and Ng, L.F., 2013. Neutrophils: neglected players in viral diseases. DNA and cell biology, 32(12), pp.665-675.

Garcia-Romo, G.S., Caielli, S., Vega, B., Connolly, J., Allantaz, F., Xu, Z., Punaro, M., Baisch, J., Guiducci, C., Coffman, R.L. and Barrat, F.J., 2011. Netting neutrophils are major inducers of type I IFN production in pediatric systemic lupus erythematosus. Science translational medicine, 3(73), pp.73ra20-73ra20.

Gasque, P. and Jaffar-Bandjee, M.C., 2015. The immunology and inflammatory responses of human melanocytes in infectious diseases. Journal of Infection, 71(4), pp.413-421.

Gupta, A.K., Joshi, M.B., Philippova, M., Erne, P., Hasler, P., Hahn, S. and Resink, T.J., 2010. Activated endothelial cells induce neutrophil extracellular traps and are susceptible to NETosis-mediated cell death. FEBS letters, 584(14), pp.3193-3197.

Huang, Y.H., Lei, H.Y., Liu, H.S., Lin, Y.S., Liu, C.C. and Yeh, T.M., 2000. Dengue virus infects human endothelial cells and induces IL-6 and IL-8 production. The American journal of tropical medicine and hygiene, 63(1), pp.71-75.

Jorch, S.K. and Kubes, P., 2017. An emerging role for neutrophil extracellular traps in noninfectious disease. Nature medicine, 23(3), p.279. 
Jorch, S.K. and Kubes, P., 2017. An emerging role for neutrophil extracellular traps in noninfectious disease. Nature medicine, 23(3), p.279.

Lam, S. K., et al. "Chikungunya infection--an emerging disease in Malaysia." (2001).

Li, P., Li, M., Lindberg, M.R., Kennett, M.J., Xiong, N. and Wang, Y., 2010. PAD4 is essential for antibacterial innate immunity mediated by neutrophil extracellular traps. Journal of Experimental Medicine, 207(9), pp.1853-1862.

Lounibos, L.P. and Kramer, L.D., 2016. Invasiveness of Aedes aegypti and Aedes albopictus and vectorial capacity for chikungunya virus. The Journal of infectious diseases, 214(suppl_5), pp.S453-S458.

Lumsden, W. H. R. "An epidemic of virus disease in Southern Province, Tanganyika territory, in 1952-1953 II. General description and epidemiology." Transactions of the Royal Society of Tropical Medicine and Hygiene 49.1 (1955): 33-57.

Mahalingam, S., Meanger, J., Foster, P.S. and Lidbury, B.A., 2002. The viral manipulation of the host cellular and immune environments to enhance propagation and survival: a focus on RNA viruses. Journal of leukocyte biology, 72(3), pp.429-439.

Martinelli, S., Urosevic, M., Daryadel, A., Oberholzer, P.A., Baumann, C., Fey, M.F., Dummer, R., Simon, H.U. and Yousefi, S., 2004. Induction of genes mediating interferon-dependent extracellular traps formation during neutrophil differentiation. Journal of Biological Chemistry. 
Mavale, Mangala, et al. "Venereal transmission of chikungunya virus by Aedes aegypti mosquitoes (Diptera: Culicidae)." The American journal of tropical medicine and hygiene 83.6 (2010): 1242-1244.

McDonald, B., Davis, R.P., Kim, S.J., Tse, M., Esmon, C.T., Kolaczkowska, E. and Jenne, C.N., 2017. Platelets and neutrophil extracellular traps collaborate to promote intravascular coagulation during sepsis in mice. Blood, pp.blood2016.

Ministério da Saúde. Secretaria de Vigilância em Saúde. Monitoramento dos casos de dengue, febre de chikungunya e febre pelo vírus Zika até a Semana Epidemiológica 25, 2017. Boletim Epidemiológico. 2017;48(20):1-10. Disponível em:http://combateaedes.saude.gov.br/images/boletinsepidemiologicos/Boletim2 017_020-Monitoramento-dos-casos-de-dengue-febre-de-chikungunya-e-febrepelo-Zika.pdf

Moreno-Altamirano, M.M.B., Rodríguez-Espinosa, O., Rojas-Espinosa, O., Pliego-Rivero, B. and Sánchez-García, F.J., 2015. Dengue virus serotype-2 interferes with the formation of neutrophil extracellular traps. Intervirology, 58(4), pp.250-259.

Nunes, Marcio Roberto Teixeira, et al. "Emergence and potential for spread of Chikungunya virus in Brazil." BMC medicine 13.1 (2015): 102.

Palha, N., Guivel-Benhassine, F., Briolat, V., Lutfalla, G., Sourisseau, M., Ellett, F., Wang, C.H., Lieschke, G.J., Herbomel, P., Schwartz, O. and Levraud, J.P., 2013. Real-time whole-body visualization of Chikungunya Virus infection and host interferon response in zebrafish. PLoS pathogens, 9(9), p.e1003619. 
Papayannopoulos, V., 2018. Neutrophil extracellular traps in immunity and disease. Nature Reviews Immunology, 18(2), p.134.

Papayannopoulos, V.; Metzler, K.D.; Hakkim, A.; Zychlinsky, A. Neutrophil elastase and myeloperoxidase regulate the formation of neutrophil extracellular traps. J. Cell Biol. 2010, 191, 677-691.

Perrone, L.A., Plowden, J.K., García-Sastre, A., Katz, J.M. and Tumpey, T.M., 2008. H5N1 and 1918 pandemic influenza virus infection results in early and excessive infiltration of macrophages and neutrophils in the lungs of mice. PLoS pathogens, 4(8), p.e1000115.

Powers, Ann M., and Christopher H. Logue. "Changing patterns of chikungunya virus: re-emergence of a zoonotic arbovirus." Journal of General Virology 88.9 (2007): 2363-2377.

Pu, J., Guardia, C.M., Keren-Kaplan, T. and Bonifacino, J.S., 2016. Mechanisms and functions of lysosome positioning. J Cell Sci, 129(23), pp.4329-4339.

Raftery, M.J., Lalwani, P., Krautkrämer, E., Peters, T., Scharffetter-Kochanek, K., Krüger, R., Hofmann, J., Seeger, K., Krüger, D.H. and Schönrich, G., 2014. B2 integrin mediates hantavirus-induced release of neutrophil extracellular traps. Journal of Experimental Medicine, 211(7), pp.1485-1497.

Rashad, A.A., Mahalingam, S. and Keller, P.A., 2014. Chikungunya virus: emerging targets and new opportunities for medicinal chemistry. J. Med. Chem, 57(4), pp.1147-1166. 
Reilly, J.P., Anderson, B.J., Hudock, K.M., Dunn, T.G., Kazi, A., Tommasini, A., Charles, D., Shashaty, M.G., Mikkelsen, M.E., Christie, J.D. and Meyer, N.J., 2016. Neutropenic sepsis is associated with distinct clinical and biological characteristics: a cohort study of severe sepsis. Critical Care, 20(1), p.1.

Robinson, Marion C. "An epidemic of virus disease in Southern Province, Tanganyika territory, in 1952-1953." Transactions of the Royal Society of Tropical Medicine and Hygiene 49.1 (1955): 28-32.

Rougeron, Virginie, et al. "Chikungunya, a paradigm of neglected tropical disease that emerged to be a new health global risk." Journal of clinical Virology 64 (2015): 144-152.

Saitoh, T., Komano, J., Saitoh, Y., Misawa, T., Takahama, M., Kozaki, T., Uehata, T., Iwasaki, H., Omori, H., Yamaoka, S. and Yamamoto, N., 2012. Neutrophil extracellular traps mediate a host defense response to human immunodeficiency virus-1. Cell host \& microbe, 12(1), pp.109-116.

Salonen, A.N.N.E., Ahola, T.E.R.O. and Kääriäinen, L.E.E.V.I., 2004. Viral RNA replication in association with cellular membranes. In Membrane trafficking in viral replication (pp. 139-173). Springer, Berlin, Heidelberg.

Singh, I. and Helenius, A., 1992. Role of ribosomes in Semliki Forest virus nucleocapsid uncoating. Journal of virology, 66(12), pp.7049-7058.

Smith, P.K., Wang, S.Z., Dowling, K.D. and Forsyth, K.D., 2001. Leucocyte populations in respiratory syncytial virus-induced bronchiolitis. Journal of paediatrics and child health, 37(2), pp.146-151. 
Sollberger, G., Choidas, A., Burn, G.L., Habenberger, P., Di Lucrezia, R., Kordes, S., Menninger, S., Eickhoff, J., Nussbaumer, P., Klebl, B. and Krüger, R., 2018. Gasdermin D plays a vital role in the generation of neutrophil extracellular traps. Science immunology, 3(26), p.eaar6689.

Sourisseau, M., Schilte, C., Casartelli, N., Trouillet, C., Guivel-Benhassine, F., Rudnicka, D., Sol-Foulon, N., Le Roux, K., Prevost, M.C., Fsihi, H. and Frenkiel, M.P., 2007. Characterization of reemerging chikungunya virus. PLoS pathogens, 3(6), p.e89.

Souza, P.S.S., Barbosa, L.V., Diniz, L.F.A., da Silva, G.S., Lopes, B.R.P., Souza, P.M.R., de Araujo, G.C., Pessoa, D., de Oliveira, J., Souza, F.P. and Toledo, K.A., 2018. Neutrophil extracellular traps possess anti-human respiratory syncytial virus activity: Possible interaction with the viral F protein. Virus research, 251, pp.68-77.

Thiboutot, M.M., Kannan, S., Kawalekar, O.U., Shedlock, D.J., Khan, A.S., Sarangan, G., Srikanth, P., Weiner, D.B. and Muthumani, K., 2010. Chikungunya: a potentially emerging epidemic?. PLoS neglected tropical diseases, 4(4), p.e623.

Trevelin, S.C., Dos Santos, C.X., Ferreira, R.G., de Sá Lima, L., Silva, R.L., Scavone, C., Curi, R., Alves-Filho, J.C., Cunha, T.M., Roxo-Júnior, P. and Cervi, M.C., 2016. Apocynin and Nox2 regulate NF-KB by modifying thioredoxin1 redox-state. Scientific reports, 6, p.34581.

Vega-Rúa, A., Zouache, K., Girod, R., Failloux, A.B. and Lourenço-de-Oliveira, R., 2014. High level of vector competence of Aedes aegypti and Aedes 
albopictus from ten American countries as a crucial factor in the spread of Chikungunya virus. Journal of virology, 88(11), pp.6294-6306.

Wang, W., Suzuki, Y., Tanigaki, T., Rank, D.R. and Raffin, T.A., 1994. Effect of the NADPH oxidase inhibitor apocynin on septic lung injury in guinea pigs. American journal of respiratory and critical care medicine, 150(5), pp.14491452.

Wichit, S., Diop, F., Hamel, R., Talignani, L., Ferraris, P., Cornelie, S., Liegeois, F., Thomas, F., Yssel, H. and Missé, D., 2017. Aedes Aegypti saliva enhances chikungunya virus replication in human skin fibroblasts via inhibition of the type I interferon signaling pathway. Infection, Genetics and Evolution, 55, pp.68-70.

Wojtasiak, M., Pickett, D.L., Tate, M.D., Londrigan, S.L., Bedoui, S., Brooks, A.G. and Reading, P.C., 2010. Depletion of Gr-1+, but not Ly6G+, immune cells exacerbates virus replication and disease in an intranasal model of herpes simplex virus type 1 infection. Journal of General Virology, 91(9), pp.2158-2166.

Yipp, B.G., Petri, B., Salina, D., Jenne, C.N., Scott, B.N., Zbytnuik, L.D., Pittman, K., Asaduzzaman, M., Wu, K., Meijndert, H.C. and Malawista, S.E., 2012. Dynamic NETosis is carried out by live neutrophils in human and mouse bacterial abscesses and during severe gram-positive infection. Nature medicine, 18(9), p.1386.

Zaid, A., Gérardin, P., Taylor, A., Mostafavi, H., Malvy, D. and Mahalingam, S., 2018. Chikungunya Arthritis: Implications of Acute and Chronic Inflammation Mechanisms on Disease Management. Arthritis \& Rheumatology, 70(4), pp.484-495. 
Zhang, R., Kim, A.S., Fox, J.M., Nair, S., Basore, K., Klimstra, W.B., Rimkunas, R., Fong, R.H., Lin, H., Poddar, S. and Crowe, J.E., 2018. Mxra8 is a receptor for multiple arthritogenic alphaviruses. Nature, p.1.

Zhu, L., Liu, L., Zhang, Y., Pu, L., Liu, J., Li, X., Chen, Z., Hao, Y., Wang, B., Han, J. and Li, G., 2018. High level of neutrophil extracellular traps correlates with poor prognosis of severe influenza A infection. The Journal of Infectious Diseases, 217(3), pp.428-437. 